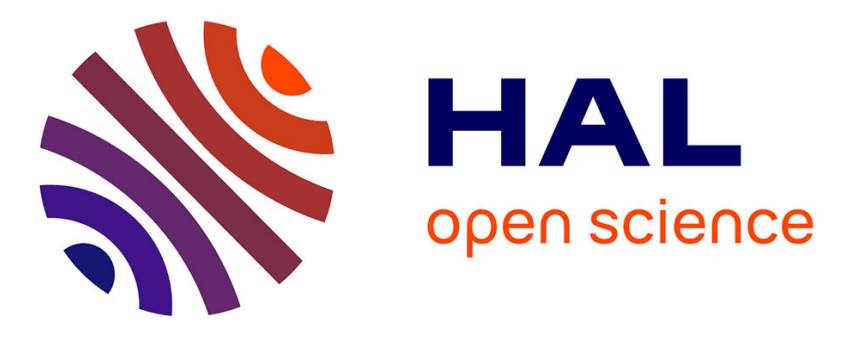

\title{
The depositional signature of cyclic steps: A late Quaternary analogue compared to modern active delta slopes
}

\author{
Jean-François Ghienne, Alexandre Normandeau, Pierre Dietrich, Melanie \\ Bouysson, Patrick Lajeunesse, Mathieu Schuster
}

\section{To cite this version:}

Jean-François Ghienne, Alexandre Normandeau, Pierre Dietrich, Melanie Bouysson, Patrick Lajeunesse, et al.. The depositional signature of cyclic steps: A late Quaternary analogue compared to modern active delta slopes. Sedimentology, 2021, Special Issue: Supercritical - flow processes and products, 68 (4), pp.1502-1538. 10.1111/sed.12806 . insu-02960340v2

\section{HAL Id: insu-02960340 \\ https://hal-insu.archives-ouvertes.fr/insu-02960340v2}

Submitted on 26 Nov 2020 (v2), last revised 28 Jun 2021 (v3)

HAL is a multi-disciplinary open access archive for the deposit and dissemination of scientific research documents, whether they are published or not. The documents may come from teaching and research institutions in France or abroad, or from public or private research centers.
L'archive ouverte pluridisciplinaire HAL, est destinée au dépôt et à la diffusion de documents scientifiques de niveau recherche, publiés ou non, émanant des établissements d'enseignement et de recherche français ou étrangers, des laboratoires publics ou privés. 


\title{
The depositional signature of cyclic steps: A late Quaternary analogue compared to modern active delta slopes
}

\author{
JEAN-FRANÇOIS GHIENNE*, ALEXANDRE NORMANDEAU†, PIERRE DIETRICH $₫ ₫$, \\ MELANIE BOUYSSON*, PATRICK LAJEUNESSE§ and MATHIEU SCHUSTER* \\ * Institut de Physique du Globe de Strasbourg, UMR 7516 CNRS/Université de Strasbourg, 1 rue Blessig, 67084 \\ Strasbourg, France (E-mail: ghienne@unistra.fr) \\ $\uparrow$ Geological Survey of Canada (Atlantic), Natural Resources Canada, Dartmouth, Nova Scotia, B2Y 4A2, Canada \\ $\ddagger$ Department of Geology, Auckland Park Kingsway Campus, University of Johannesburg, Johannesburg, South Africa \\ `Géosciences Rennes, UMR6118, Université de Rennes 1, 263 Avenue du Général Leclerc, Bâtiment 15, Campus de \\ Beaulieu, 35042 Rennes Cedex, France. \\ §Département de Géographie, Université Laval, Québec, Québec G1V 0A6, Canada
}

Associate Editor - Arnoud Slootman

\begin{abstract}
Cyclic-step bedforms typifying a Froude-supercritical flow regime are a recurrent component of depositional/erosional turbiditic systems. Over modern delta slopes, cyclic steps have been inferred from observations of upslope-migrating crescent-shaped bedforms. However, the recognition in the sedimentary record of the resulting stratal pattern and depositional facies remains challenging. In this study, the depositional facies observed in exposed late Quaternary glaciofluvial upper delta-slope sands (Portneuf-Forestville, Québec) are compared to those cored from a modern analogue consisting of sediment waves interpreted as cyclic steps (Southwind Fjord, Baffin Island). The fossil and modern delta slopes share similar context, morphology and stratigraphic record. The clinoform foresets dip 2 to $6^{\circ}$ and consist of prevailing sandsized material including subhorizontal to upslope-dipping top-cut-out turbidites. Individually, the latter are 5 to $20 \mathrm{~cm}$ thick and massive to planar laminated (prevailing $\mathrm{T}_{\mathrm{A}}$ and $\mathrm{T}_{\mathrm{B}}$ subdivisions). In the fossil delta slope, related successions form relatively thick, well-bedded suites, which are truncated downcurrent by, and onlap upstreamward on inclined composite erosion surfaces here referred to as pseudoforesets. Pseudo-foresets are regularly spaced (10 to $30 \mathrm{~m}$ ) and have dips greater than the clinoform foresets $\left(\sim 20^{\circ}\right)$. Large composite scours form pseudo-channel structures filled-in by structureless pebbly sand deformed by sheared flame structures, in association with coarse sand showing undulating lamination and rip-up clasts. Similar depositional facies are observed on the modern delta slope. The stratal pattern is best compatible with upslope-migrating bedforms and structureless sand indicates hydraulic jump deposits typical of cyclic steps. Cyclic-step flow events, encompassing a succession of genetically linked erosional cyclic steps, depositional cyclic steps and subsequent waning-flow conditions, were associated with the dense basal layer of highdensity (stratified) turbidity currents. They are specifically associated with pseudochannel incision and infill. The deposition of well-bedded suites on the stoss side, occasionally also on the lee side, is interpreted to result from a different type of turbidity current, which decelerated over the bedform stoss and accelerated over the lee sides of pre-existing cyclic-step morphologies. Antidunal flow conditions in expanded (non-stratified) turbidity currents are tentatively suggested, deposition being linked, in this case, to interactions between inherited bedform morphologies and a near-bed tractive layer. In the resulting dual flow model, the bulk of delta-slope sands was mainly deposited from turbidity currents not developing a cyclic-step instability, yet cyclic steps were instrumental in shaping and/or re-organizing the delta-slope morphology, bedforms and resulting stratal patterns. In some delta systems, the upslope migration of supercritical crescentic bedforms may not be only due to repetitive cyclic steps but could also result from antidunal turbidity current conditions remobilizing an inherited cyclically-stepped morphology.
\end{abstract}

KEYWORDS Bedforms; delta foreset; Eastern Canada; high-density turbidites; supercritical flows. 


\section{INTRODUCTION}

In recent years cyclic steps have been recognized as a recurrent component of depositional/erosional turbiditic systems and have been observed from the deep-sea to shallow waters of lacustrine and marine delta slopes (Fildani et al., 2006; Cartigny et al., 2011; Kostic, 2011; Fricke et al., 2015; Turmel et al., 2015; Normandeau et al., 2016; Covault et al., 2017; Kostic et al., 2019; Slootman and Cartigny, 2020). The term was first coined by Parker (1996) to describe both a supercritical flow instability —a flow cyclically shifting from a supercritical to subcritical regime bounded by hydraulic jumps - and the related bedforms.

Often initially described as sediment waves or crescentic bedforms (Migeon et al., 2001; Cartigny et al., 2011), cyclic steps are now increasingly understood as a common morphosedimentary signature of such supercritical flows (Kostic et al., 2010; Kostic, 2011; Cartigny et al., 2014; Postma and Cartigny, 2014; Hughes Clarke, 2016; Symons et al., 2016). The resulting bedforms are asymmetrical, often crescent-shaped in confined settings, and have been observed to migrate upslope, both in numerical and flume-tank experiments (Sequeiros et al., 2009; Spinewine et al., 2009; Yokokawa et al., 2009, 2011; Kostic, 2011; Vellinga et al., 2018). In natural case studies, related bedforms are inferred to migrate upslope from seismic stratigraphy (Covault et al., 2014; Tubau et al., 2015; Zhong et al., 2015; Li and Gong, 2018; Normandeau et al., 2019), as corroborated by repeat swath bathymetry mapping (Hughes Clarke et al., 2014; Normandeau et al., 2014, 2020; Hage et al., 2018; Vendettuoli et al., 2019). Asymmetric bedforms and their upslope migration originate from continuous or successive sediment-laden flow events combining: (i) leeside erosion linked to a Froude-supercritical regime over the relatively steep slopes; (ii) hydraulic jump processes in the trough; and (iii) deposition from sediment density flows under the subcritical regime characterizing the bedform stoss sides (Cartigny et al., 2014; Postma and Cartigny, 2014; Hughes Clarke, 2016; Hage et al., 2018; Vellinga et al., 2018; Slootman and Cartigny, 2020).

Both the cyclic-step instabilities and resulting bedforms are mostly investigated in modern active settings using a large array of imaging methods (e.g., flow monitoring, seismic stratigraphy and repeated swath bathymetry surveys). Although daily swath bathymetry surveys ( Hughes Clarke, 2016; Hage et al., 2018; Vendettuoli et al., 2019) illustrate how cyclic-step deposits might be preserved in the depositional record, the recognition of ancient cyclic-step deposits is only emerging since numerous outcrops are being revaluated based on new recognition criteria (Lang and Winsemann, 2013; Postma et al., 2014; Girard et al., 2015; Ventra et al., 2015; Dietrich et al., 2016; Lang et al., 2017; Ono and Plink-Björklund, 2018; Cornard and Pickering, 2019; Slootman et al., 2019). Some 'turbiditic' features observed in outcrops (e.g., top-cut-out turbidites displaying the $\mathrm{T}_{\mathrm{A}}$ and $\mathrm{T}_{\mathrm{B}}$ subdivisions of the conventional nomenclature for density-flow deposits, Talling et al., 2012) have been genetically linked to sand-laden cyclic steps (Postma et al., 2014; Postma and Cartigny, 2014). However, Hage et al. (2018) cored a cyclicstep bedform and found no evidence of visual diagnostic sedimentary structures neither on the stoss nor the lee side. Instead, they mainly recognized massive sand beds, which is also in contrast with flume-tank experiments documenting a variety of upstream- and downstream-facing crosslamination (e.g. Ono et al., in press). A discrepancy in terms of depositional facies thus appears to exist between what is observed in the rock record, in experiments and in modern turbidite systems. The comparison of sedimentary structures and associated stratal patterns between outcrops and modern systems therefore remains challenging (Cartigny et al., 2014; Talling et al., 2015; Vellinga et al., 2018; West et al., 2019; Englert et al., this issue). Such comparisons are however of prime importance for understanding how flow structures and bed morphologies coevolve beneath supercritical flows (Postma and Cartigny, 2014; Talling et al., 2015), in particular when considering the close associations through time and space between cyclic-step and antidune flow regimes (Cartigny et al., 2011; Yokokawa et al., 2011; Kostic et al., 2019).

The main issue with understanding the detailed distribution of sedimentary facies on modern delta slopes that are characterized by supercritical flows is that sand deposits are very difficult to core and to image internally (Hage et al., 2018), preventing both the sedimentary facies and the resulting 


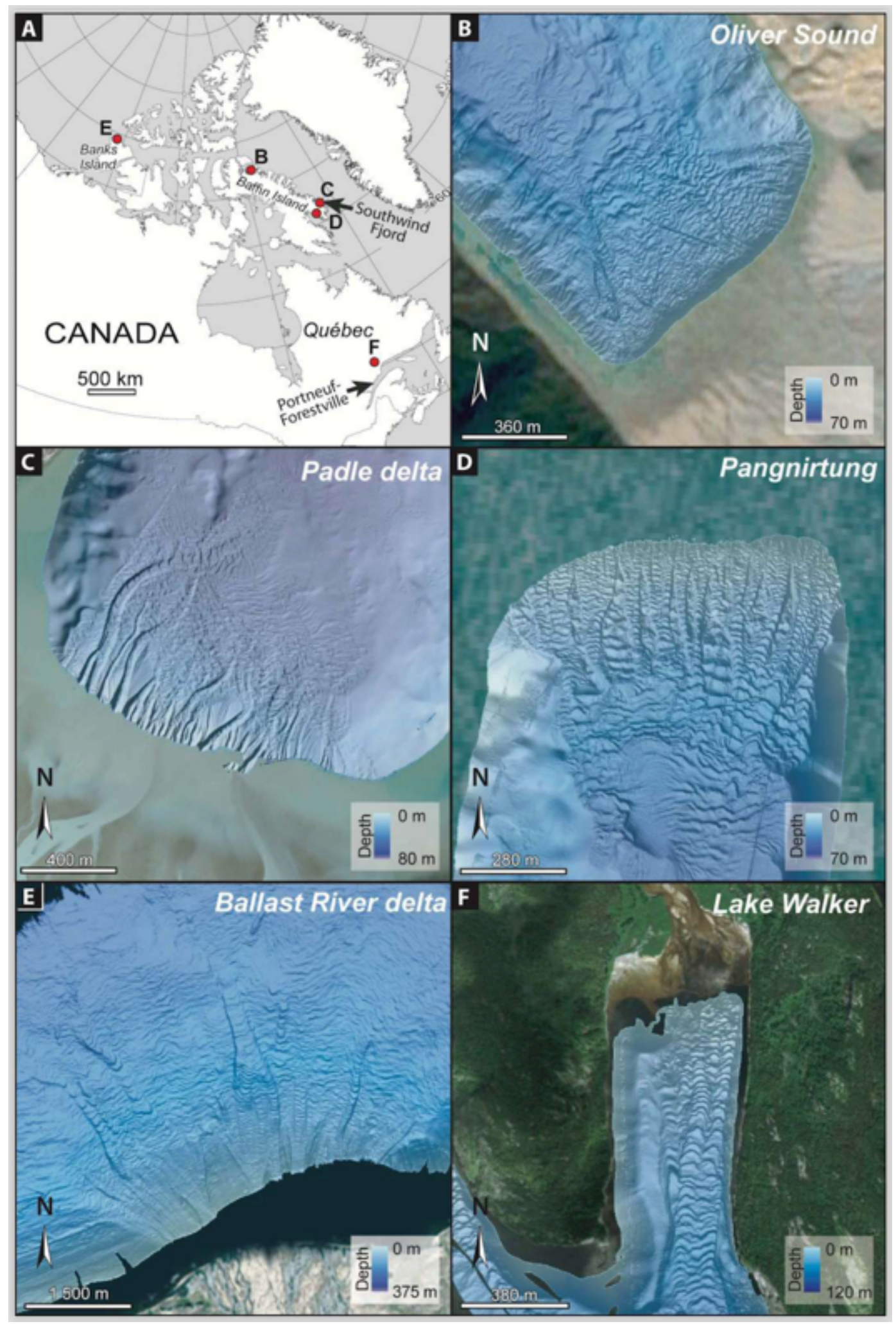

Fig. 1. Examples of delta slopes developing trains of cyclic steps, such type of bedforms being generally referred to as sediment waves or crescentic bedforms. (A) Location map. Examples around Baffin Island (B) to (D) relate to modern, active fjord-head glaciofluvial deltas (Hughes Clarke et al., 2015; Normandeau et al., 2019). Cyclic steps also characterize some postglacial open-marine (E) and lacustrine delta slopes (F). The present-day Southwind delta (Baffin Island) and the outcropping Portneuf-Forestville deltaic complex (Québec North Shore) are the two systems investigated in the present study (black arrows; see Fig. 2). 
stratal architecture to be accurately characterized. On the other hand, outcrops allow detailed investigations of the depositional facies and internal architecture, but parent flows and formative bedforms are not as well constrained as for modern systems. This study closes that gap, comparing the depositional facies observed along outcropping glaciofluvial delta-slope sands from the well-constrained late Quaternary Portneuf-Forestville delta complex (Dietrich et al., 2017a,b) to those successfully cored from a modern analogue showing welldeveloped sediment waves ascribed to cyclicstep bedforms (Southwind Fjord, Baffin Island; Normandeau et al., 2019).

The two case studies displaying very similar characteristics allow for the first time the reporting and description of depositional facies linked to cyclic steps and other supercritical flows (e.g., antidunal conditions) based on similar modern and outcrop settings. The contribution of cyclic steps to the development of delta slopes displaying cyclically-stepped morphologies is then reconsidered within the framework of a dual flow model. Combined with recent findings from the well-studied Squamish delta in British Columbia (Hughes Clarke et al., 2014; Hughes Clarke, 2016; Clare et al., 2016; Hage et al., 2018, 2019; Hizzett et al., 2018; Kostic et al., 2019; Englert et al., this issue), the dataset finally allows the discussion of the origin, the frequency and the role of cyclic steps to the accretion of sand-dominated delta slopes.

\section{SETTINGS AND METHODS}

Deposits from an outcropping fossil deltaic wedge and from a modern submarine delta slope are compared here. The diachronous deglacial evolution of the continental shelves and coasts of Canada since the Last Glacial Maximum offers a unique opportunity to investigate the entire range of deglaciation phases along with their respective sedimentary processes recorded in marine deltaic complexes via different methods. On the one hand, the present-day active glaciofluvial delta slopes of the Canadian Arctic, generally tied to fjord settings and still glacially-fed, offer the opportunity to observe ongoing sedimentary processes (Fig. 1; see also Normandeau et al., 2019). On the other hand, the Upper Pleistocene to lower Holocene glaciofluvial deltas allow investigation of depositional facies and related architecture (Dietrich et al., 2017b; Fig. 2A). Indeed, late Quaternary successions that are currently being dissected by river and/or coastal erosion after glacio-isostatic adjustment (Tarasov et al., 2012) offer in places high-quality exposures within deglacial deltaic wedges, as it is the case for the deltaic complexes of Québec (St Jean Lake area, Nutz et al., 2015; Québec North Shore, Dietrich et al., 2020). Considering that the two groups of depositional systems constitute glaciofluvial deltas fed by retreating ice margins (Syvitski, 1989; Syvitski and Praeg, 1989; Dietrich et al., 2017a; Normandeau et $a l ., 2017)$, it is argued that the settings are analogous regarding their depositional dynamics (Table 1). Note that delta slopes developing or having developed cyclic steps also exist in open-marine (Fig. 1D) or presentday lacustrine contexts (Fig. 1E; see Normandeau et al., 2016, Slootman and Cartigny, 2020 ; Trottier et al., 2020, for lacustrine case studies).

\section{Portneuf-Forestville deltaic complex}

Along the Québec North Shore (St. Lawrence Estuary and Gulf, eastern Canada), the Late Pleistocene to Holocene deglacial sequence (Occhietti et al., 2011; and references therein) is essentially represented by deltaic complexes emplaced in a deglacial to postglacial sea under conditions of glacioisostatically falling relative sea-level (Dietrich et al., 2020). These deltaic complexes individually represent sediment accumulations that are several tens to hundreds of $\mathrm{km}^{2}$ in area and $>50 \mathrm{~m}$ thick (Fig. 2A). From base to top, three main sediment bodies are usually distinguished (Fig. 3A; Dietrich et al., 2017a,b). The lower sediment body consists of well-stratified alternating glaciomarine sand and silt (green colour in Fig. 3A). This body represents the distal segment of subaqueous ice-contact fans emplaced in front of the still-standing margin of the Laurentide Ice Sheet. The intermediate sediment body comprises a well-expressed tripartite architecture related to clinoform progradation and including heterolithic bottomsets (lower delta slope; blue colour in Fig. 3A), sandy foresets (upper delta slope; red colour) and sandy to gravelly topsets (delta plain; purple colour). The composite sediment body is interpreted as a glaciofluvial deltaic wedge emplaced beyond a continental ice margin that was retreating 

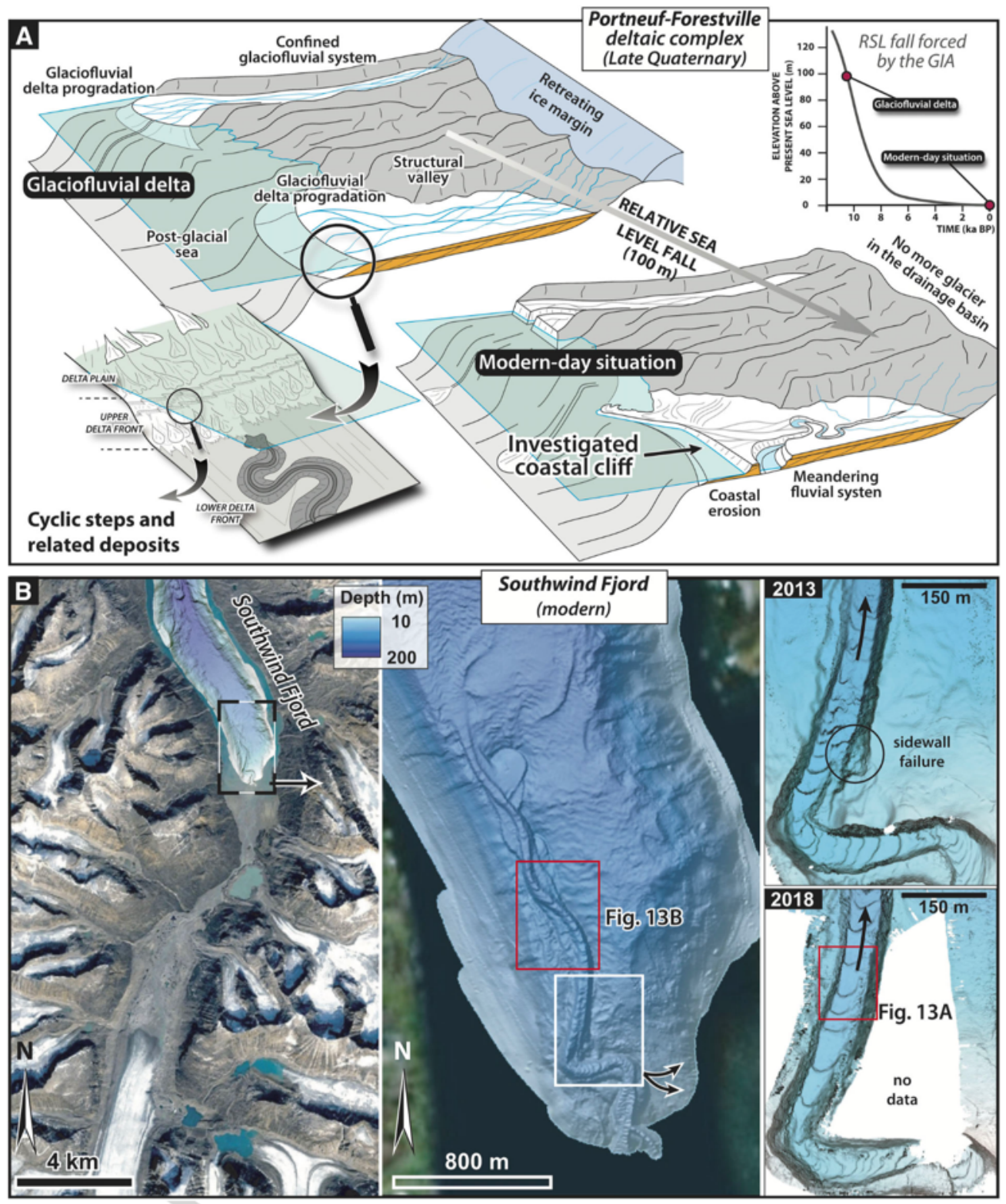

Fig. 2. Depositional settings (locations in Fig. 1). (A) 3D diagram illustrating the late Quaternary development of the Portneuf-Forestville deltaic complex (Québec North Shore; location in Fig. 1); the sediment wedge deposited in front of a retreating continental ice margin is currently uplifted owing to the glacio-isostatic adjustment. Largely dissected by present-day coastal erosion, it offers a $7 \mathrm{~km}$ long, up to $85 \mathrm{~m}$ high depositional transect including the here-studied delta-slope sands (Fig.3A; see also Dietrich et al., 2017b, 2020). (B) The proglacial context of the Southwind Fjord (Cumberland Peninsula, SE Baffin Island) and detailed bathymetric maps (2013 and 2018, localized by the white box) of the Southwind Fjord delta slope. Red frames are locations related to Fig. 13A and B. 

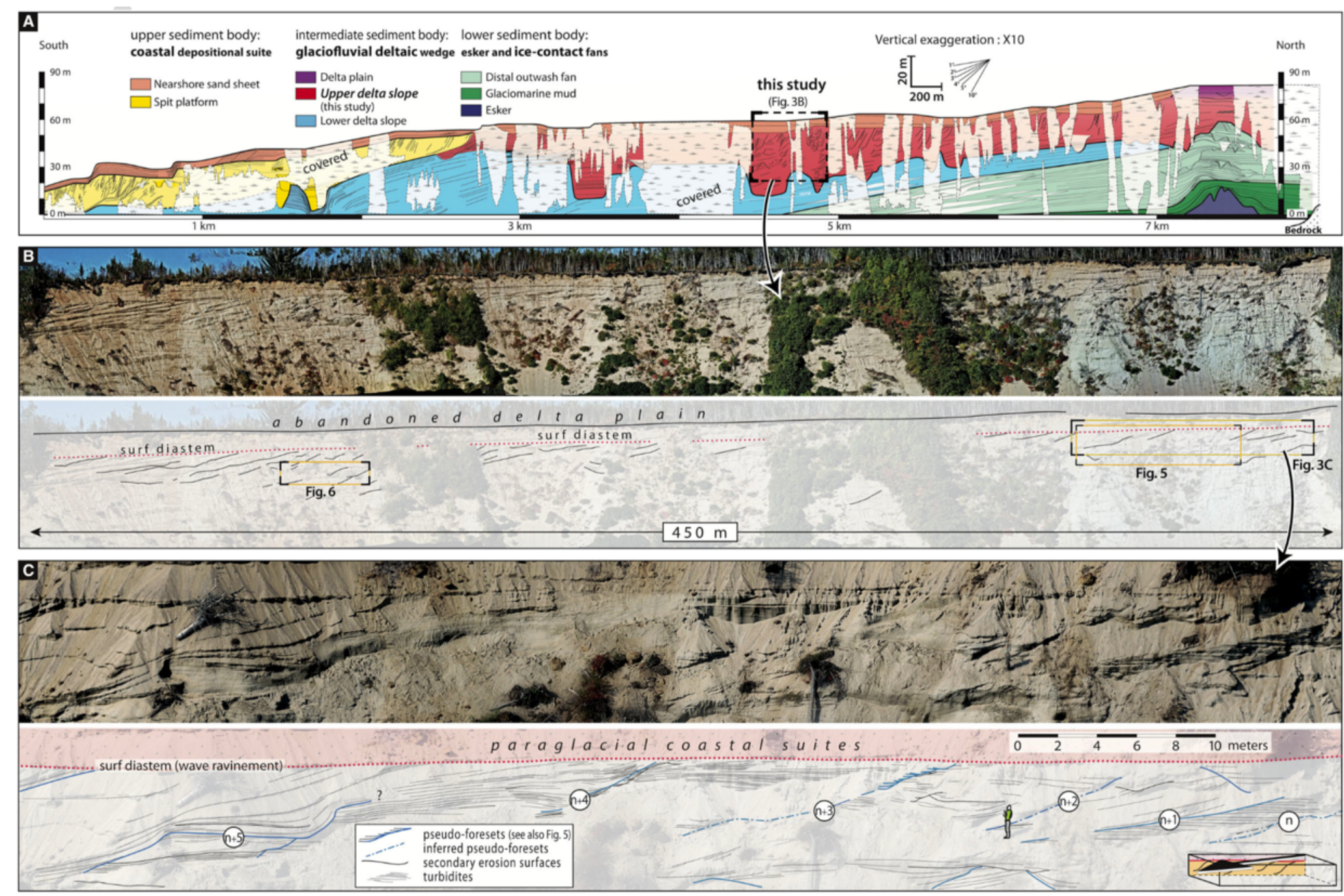

Fig. 3. Depositional architecture of the Portneuf-Forestville deltaic complex. (A) Interpreted depositional units, redrawn from Dietrich et al. (2017b). The case study is comprised within the upper delta-slope deposits (red colour) belonging to the intermediate sediment body. (B) Photomosaic of the study area (location in A) with locations of some other zoomed-in figures. (C) Orthophotomosaic of the northern segment of the study area, essentially showing a cyclic alternation of well-bedded suites and up to 6 pseudo-foresets ( $\mathrm{n}$ to $\mathrm{n}+5$; see Fig. 5 for a detailed description; no vertical exaggeration except for A). 
Table 1. Comparing physiographic and depositional contexts of the late Quaternary and modern case studies.

Portneuf-Forestville

(late Quaternary)

\section{Physiographic context}

Location of the fluvioglacial delta, latitude

Catchment area and feeder glacier

Distance from the shore to the ice front

(i.e., length of proglacial river)

Height of the clinoform foresets

(i.e., progradation depth)

\section{Depositional context}

Prevailing sediment class

Channel width

Channel length

Depositional depth

Mean depositional slope at the study site

Location along the delta-slope channel

Main period of delta activity fjord mouth, $48.80^{\circ} \mathrm{N}$

(Dietrich et al., 2017b)

5015 km², Laurentide Ice Sheet

ca. $100-130 \mathrm{~km}$

(inferred; Dietrich et al., 2017a,b)

$90 \mathrm{~m}<\mathrm{h}<180 \mathrm{~m}$

(Normandeau et al., 2017) medium to coarse sand

(Figs. 10, 11)

50-250 $\mathrm{m}$ (from scours at the channel-lobe transition, Fig. 3A)

3-5 km

ca. 20-60 m (reconstructed, Dietrich et al., 2017b)

5-6 $6^{\circ}$ (Fig. 5)

upper segment

freshet (May-July?) and autumn storms
Southwind Fjord

(present-day)

fjord-head, $66.75^{\circ} \mathrm{N}$

(Normandeau et al., 2019)

$264 \mathrm{~km}^{2}$, valley glacier

$9 \mathrm{~km}$ (Fig. 2B)

200 m (Fig. 2B) medium to coarse sand

(Fig. 14)

75 m (Fig. 2)

$2.5 \mathrm{~km}$

86-87 m (grab samples, Fig. 13A)

$2-3^{\circ}$

middle segment

June - end of August (turbid plumes in 2018 satellite images) 
over the Laurentian Highlands of the Canadian Shield. The upper sediment body forms an erosion-based, downstepping sand sheet. It is interpreted as a coastal depositional suite (yellow and orange colours), the setup of which highlights the retreat of the ice margin from the drainage basins and the subsequent shutdown of massive glaciogenic sediment supply (Dietrich et al., 2017a,b; Normandeau et al., 2017). Distal fine-grained counterparts are recognized in the offshore setting (Praeg et al., 1992; Duchesne et al., 2010; Normandeau et al., 2017).

This paper focuses on the sedimentary architecture and depositional facies of the upper delta-slope deposits (sandy delta foresets) of the intermediate sediment body (Fig. 3A, red colour). These deposits are particularly well exposed along the up to 85 $\mathrm{m}$ high coastal cliff dissecting the PortneufForestville deltaic complex (Dietrich et al., $2017 \mathrm{~b})$. The lower bounding surface is a truncation surface, showing 150 to $400 \mathrm{~m}$ wide large-scale incisions cut into the lower delta-slope deposits, which reflect scour processes linked to flow deconfinement at the toe of delta-slope channels (Massari and Parea, 1990; Gobo et al., 2014; Pohl et al., 2019). The upper segment of the upper delta slope deposits consists of a variety of depositional facies, amongst which are the sand-dominated deposits described here (facies S4 in Dietrich et al., 2017b). These deposits are truncated by a gravelly lag reflecting a surf diastem in the sense of Swift et al. (2003), i.e., a surface cut by the seaward shift of the surf zone (Fig. 3C; Dietrich et al., 2017b). Geometrical reconstruction of the prograding architecture shows that a minimal estimate for the height of the original clinoform foresets is $90 \mathrm{~m}$, with depositional depths for the upper delta-slope sands being in the 20 to $60 \mathrm{~m}$ range (Dietrich et al., 2017b). Dips of the clinoform foresets are $<3^{\circ}$ for the lower delta slope deposits, while up to $6^{\circ}$ dips characterize the sandier upper delta slope deposits.

A particularly well-exposed $450 \mathrm{~m}$ long segment of the Portneuf-Forestville sea cliff (Fig. 3B) was investigated during fieldwork (2017). In addition to panoramic photographs shot from the beach, an unmanned aerial vehicle (DJI Mavic Pro; DJI, Shenzhen, China) was used and offered wide-angle and close-up views, both oblique and orthogonal to the cliff. Orthophotomosaics were created using Agisoft Photoscan software, allowing for projections reducing deformation due to relief heterogeneities and perspectives. At the outcrop, the most interesting segments were cleaned using shovel and trowel, detailed sections were logged, noting sedimentary structures, grain sizes and attributes of stratigraphic surfaces. A selection of sand was sampled for quantitative laser diffraction grain-size analysis using a Beckman Coulter LS230 (Indianapolis, Indianan, USA).

\section{Southwind Fjord, Baffin Island}

Large parts of the Arctic depositional systems are composed of fjord deltas built - and currently building - during deglaciation (Figs 1 and 2B). The glaciers of the region are currently retreating due to ongoing climate change (Gardner et al., 2011), which provide meltwater and sediments to fjord deltas. The large volumes of sediment allow the formation of turbidity currents and sediment waves on delta fronts (Normandeau et al., 2019). Although sediment waves are observed in many channels of the fjord deltas of Baffin Island (Fig. 1; Hughes Clarke et al., 2015), this study focuses more specifically on the Southwind Fjord delta slope (Fig. 2B).

Southwind Fjord is located in Cumberland Peninsula (south-eastern Baffin Island, Fig. 1A). The delta is fed by glacial meltwater, which supplies sediment for turbidity currents to form in a long-running $(2.5 \mathrm{~km})$ submarine channel (Fig. 2B). The main glacier feeding the delta lies at only 9 $\mathrm{km}$ from the fjord head. Between the glacier and the fjord, a large delta plain (sandur delta) formed during glacial retreat. The fjord is $200 \mathrm{~m}$ deep, with steep-sided slopes and a submarine channel enclosing crescentic bedforms interpreted as cyclic steps on the basis of bedform shape and repeat swath bathymetries (Normandeau et al., 2019).

The Southwind Fjord dataset consists of swath bathymetry data collected on the R/V Nuliajuk (2013), the CCGS Amundsen (2014) and the CCGS Hudson (2018). The repeat swath bathymetry over these three surveys allowed observation of the signature of turbidity current activity in the fjord. In addition to swath bathymetry, sediment samples were collected in the morning of August 28, 2018 from a bedform that was mapped during the night of August 27-28, 2018 (Fig. 4; Normandeau et al., 2018). Therefore, the sedimentary structures in grab samples represent recent deposits of the 

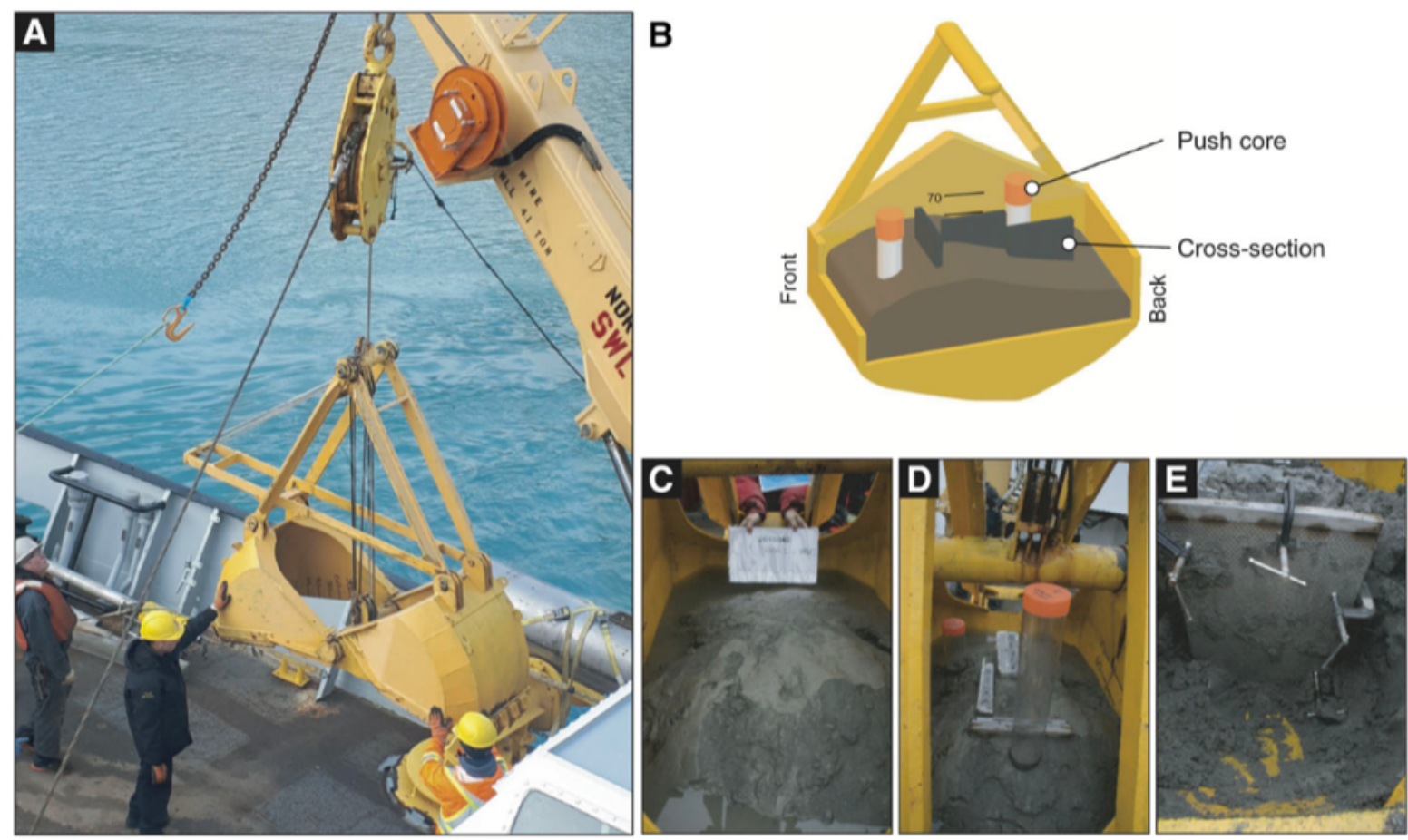

Fig. 4. Grab sampling. (A) IKU grab sampler ready for deployment. (B) 3D representation of an IKU grab with sediment inside. Cross sections and push cores were collected from the grab. (C) to (E) Examples of cross-sections being collected from the grab sampler. 
crescentic bedform. The collection method used large $\left(1 \mathrm{~m}^{3}\right)$ sand grabs (e.g. Amos et al., 2003; Li and King, 2007), where deformation from impact (e.g., piston cores) is negligible (Fig. 4). The grab closes gently through the sediment in order to not disturb the preserved sedimentary structures. Once the grab is back at the surface, two opposing aluminum sections (30 $\mathrm{cm}$ by $60 \mathrm{~cm}$ ) were gently pushed into the sediment and squeezed using clamps. The sand around the sections was then removed and the sections were placed on a table and scraped to investigate sedimentary structures. Three sand grabs were collected on one individual cyclic-step bedform, which is $60 \mathrm{~m}$ in wavelength and lies at a depth of 85 to $88 \mathrm{~m}$. The three grabs were positioned in the trough, on the stoss and near the crest of the bedform to examine the along-slope evolution of sedimentary structures within a single bedform. The GPS positioning of the corer and its weight guaranteeing a subvertical descent in shallow and calm water allow to estimate the maximum uncertainty on the position of the samples at within a $5 \mathrm{~m}$ radius. It gives us confidence that the observed sedimentary structures truly represent the stoss side of the bedform, from the trough to the crest.

\section{THE PORTNEUF-FORESTVILLE CASE STUDY}

The upper delta slope deposits of the Portneuf-Forestville deltaic complex display sets, bedsets and erosional bedset boundaries (Figs 3, 5 to 7) and show structureless and planar laminated sand, more rarely ripple cross-lamination, and a variety of softsediment deformation structures (Figs 5 to 9). While medium to coarse sand prevails (Figs 10 and 11), mud layers and conglomeratic lenses represent subordinate deposits. Insets in Fig. 6 show a selection of architectural patterns and sedimentary structures found in the upper delta slope.

\section{Stratal patterns}

Erosional bedset boundaries are ubiquitous in the upper delta slope deposits. At the exposure, first-order features correspond either to relatively steep offlapping surfaces (Figs 3, 5, 6, 7A and B) or to deep scours (Figs 5, 6 and 8). Offlapping surfaces are best identified on dip-oriented sections parallel to palaeoflow and deep scours are preferentially observed in cross-sections perpendicular to palaeoflow. Close-up views reveal that the two types of bedset boundary were formed by the amalgamation of superimposed scours of various amplitudes and geometries. In the following description, they are referred to as pseudo-foresets and pseudo-channels, respectively, since from a distance and at first glance these bedset boundaries suggest clinoform foresets (Fig. 3) and channel structures (Figs 5 and 8). Although the geometry of the junction between the two types of bedset boundary remains unclear, both are attributed to a unique system of composite erosion surfaces. The aspect of the latter differs according to the orientation of the studied cross-section relative to the palaeoflow direction.

Pseudo-foresets have vertical development in the 4 to $10 \mathrm{~m}$ range and show $\sim 20^{\circ}$ dips. They appear as the result of a superimposition of backstepping, dm-deep to m-deep, spoon-shaped scours (Figs 5 and 7). Individual scours are highly asymmetrical in sections parallel to palaeoflow. Upstreamward, each scour corresponds to a steep, in some cases subvertical, erosional contact truncating abruptly the underlying sand beds (Fig. 6). The scour surface is generally underlined by a distinctive $\mathrm{mm}$-scale layer rich in heavy minerals (Fig. 7B). Downslope, the scour surface progressively grades into one of the subhorizontal paraconformable to conformable bed contacts characterizing the well-bedded suites described below. In sections perpendicular to the palaeoflow, the envelope of a pseudo-channel, which also is the result of the juxtaposition of successive scour surfaces (Figs 5 and 8), is 10 to $30 \mathrm{~m}$ wide and shows vertical amplitudes in the 1 to $4 \mathrm{~m}$ range. Steep $\left(>40^{\circ}\right)$ erosional contacts, locally subvertical, are generally observed, the dip of which is essentially perpendicular to the palaeoflow (Fig. 5). In places, pseudochannel margins merge up-section with the lower segment of a pseudo-foreset (Fig. 6).

Irrespective of their orientation, steep contacts typifying both the pseudo-foresets and pseudo-channels are spatially associated with gravitational deformation in the truncated, immediately underlying sand beds as shown by arrays of small extensional stepped fractures or by translated sand masses (in red in Figs 5 and 6; close-up view in Fig. 8B). Small-scale (10 to $30 \mathrm{~cm}$ ) translated sand masses, the offsets of which are less than $0.5 \mathrm{~m}$, are preferentially preserved beneath the lower segments of the 


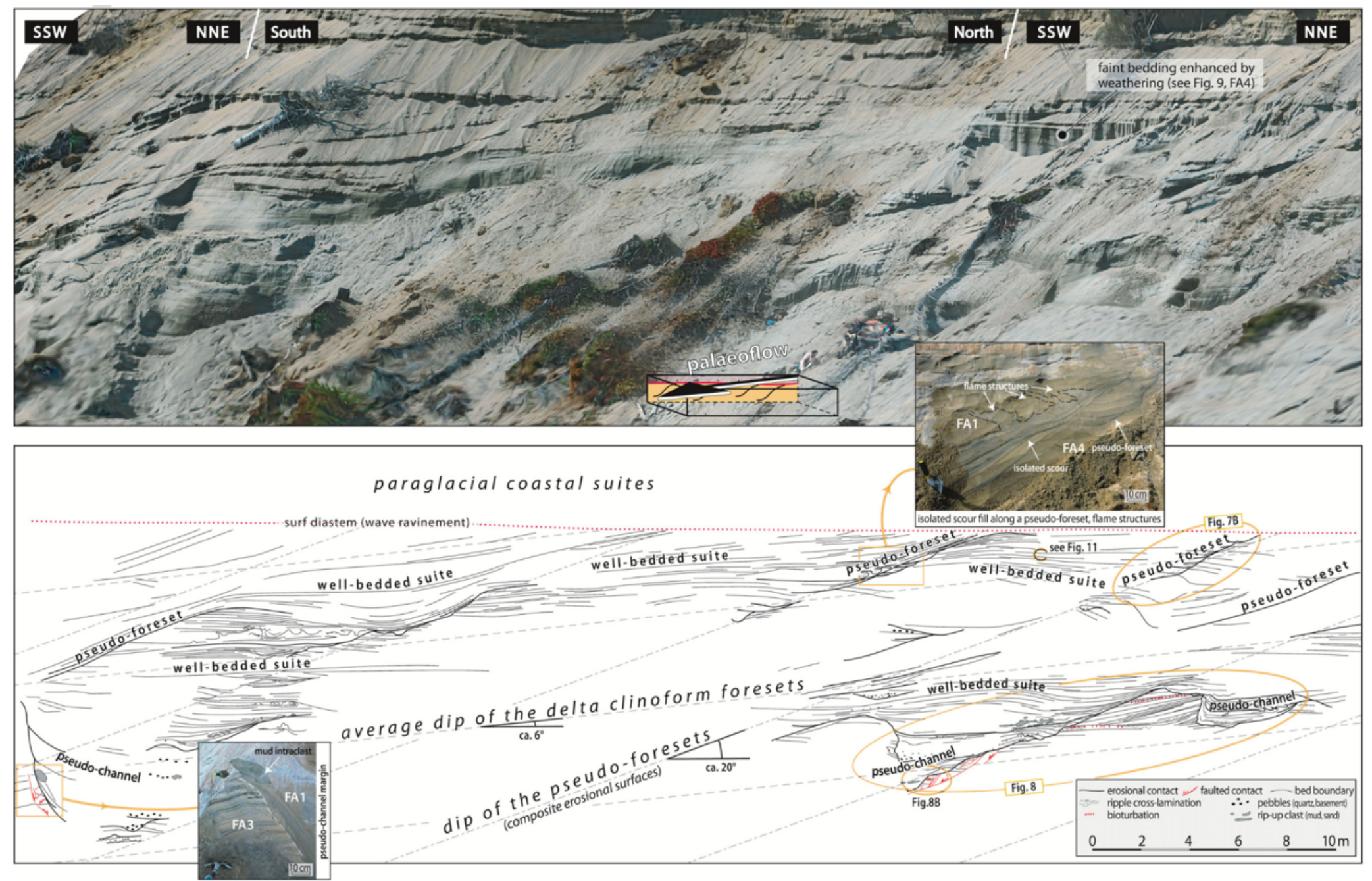

Fig. 5. Orthophotomosaic of a northern portion of the study area (see location in Fig. 3B) and its interpretation, differentiating the main bed boundaries and intervening erosion surfaces and showing relationships between pseudo-foresets, well-bedded suites and pseudo-channels. These deposits are truncated by a gravelly lag interpreted as a surf diastem reflecting forced regression (Dietrich et al., 2017b). The low-angle and steeper grey dotted lines highlight the inferred "average" dip of the delta clinoform foreset and the dips of the pseudo-foresets, respectively. Insets show a pseudo-channel margin (lower left) and an isolated scour fill and associated cyclic-step deposits with sheared flame structures (upper right). 

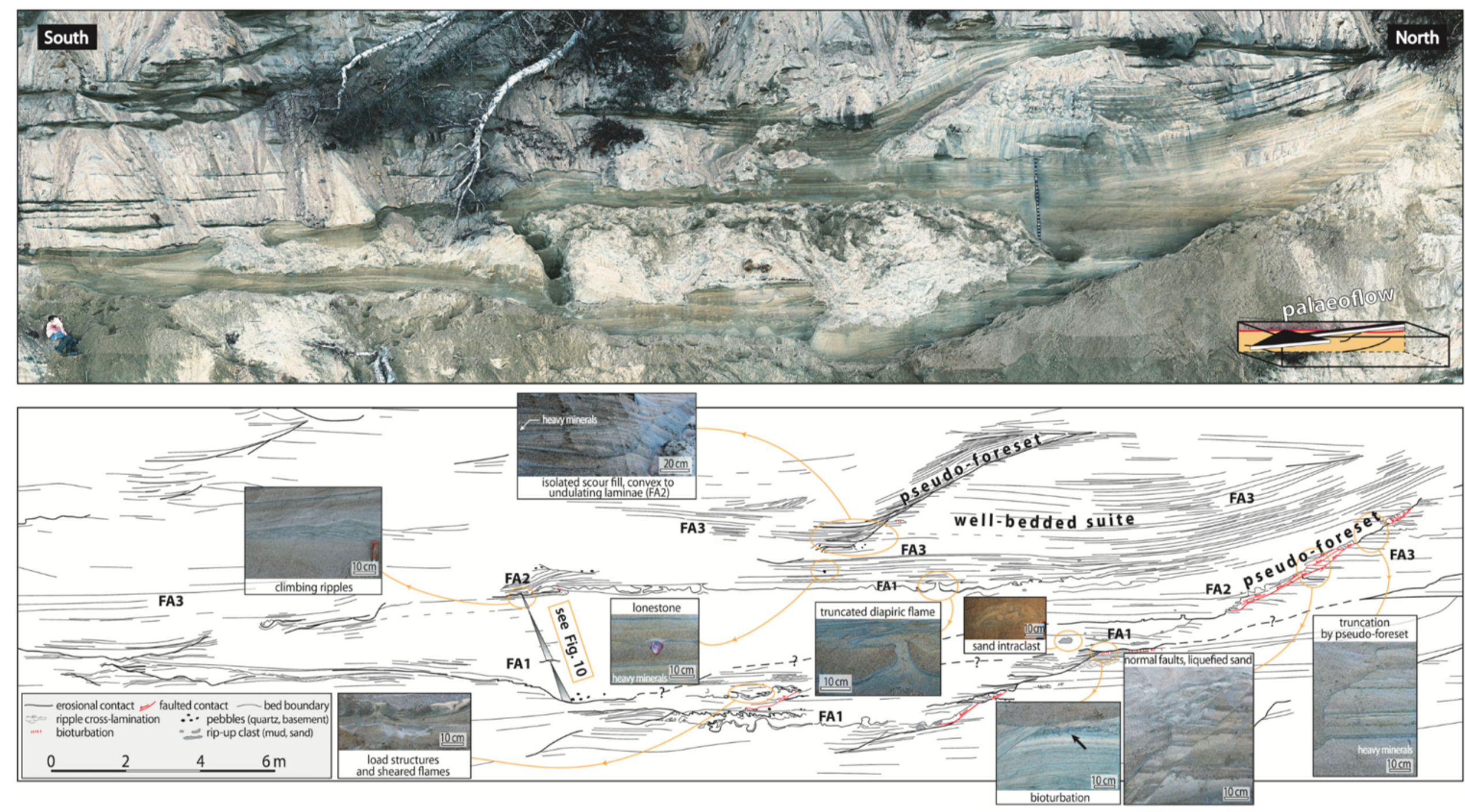

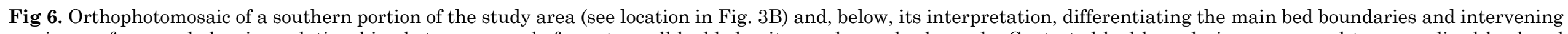

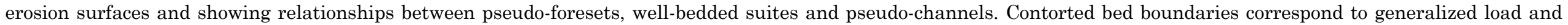

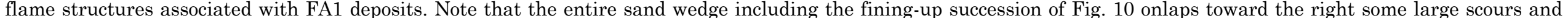

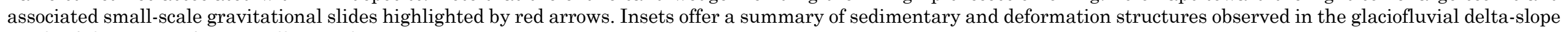
sands of the Portneuf-Forestville complex. 
pseudo-foresets. Larger-scale $(<1 \mathrm{~m})$ sand masses translated above listric faults showing up to $2 \mathrm{~m}$ vertical offsets typify the steeper margins of the pseudo-channels. In places, sand masses are affected by liquefaction to fluidization processes.

Well-bedded suites, which are another striking architectural element of the delta-slope sands, are observed between two successive pseudo-foresets and generally overlie pseudo-channel infills. Well-bedded suites are organized into 2 to $10 \mathrm{~m}$ thick successions of paraconformable, subhorizontal to gently undulating sand beds, which have lateral extent in the 10 to $40 \mathrm{~m}$ range (Figs $3 \mathrm{C}, 5$ and 6). At their upstream termination, sand beds are curved-up and abut against, or tend to be sub-parallel to an underlying pseudo-foreset that shows up to $20^{\circ}$ dips. They progressively become subhorizontal downslope, forming several meters thick bedsets with internal paraconformable to conformable bed contacts. At their downstream toe, beds forming a particular well-bedded suite are truncated by the next pseudo-foreset (Figs 5, 6 and 7A). In between two successive pseudo-foresets, and preferentially in views more or less parallel to local palaeocurrent trends, the bed layout may show a gentle undulation of large $(>10$ $\mathrm{m})$ wavelength yet of limited $(<0.5 \mathrm{~m})$ amplitude, which includes three segments (Fig. 5): (i) a first short segment with up to $15^{\circ}$ downslope dips is noted immediately downstream of a pseudo-foreset, before rapid bed horizontalization; (ii) along most of their length, beds are subhorizontal or dip slightly $\left(<2^{\circ}\right)$ upstream, thus corresponding to a faint backstepping layout (Figs 5 and 11); and (ii) beyond a gentle crest starts the third segment, along which downslope-facing dips renew, before beds are sharply truncated by the next pseudo-foreset.

\section{Facies associations}

Two main depositional configurations are identified in the upper delta slope deposits: (i) cut-and-fill deposits typifying the pseudochannels; and (ii) well-bedded suites in close association with series of pseudo-foresets. Both configurations are further subdivided into two distinct facies associations (FA). Thus, four facies associations are described (Fig. 9 and Table 2). Pseudo-channel deposits include FA1: amalgamated lenticular bodies of structureless coarse sand and gravel and FA2: coarse sand with undulating lamination. Well-bedded suites are mediumto coarse-grained deposits forming the bulk of the upper delta slope deposits. They show either FA3: top-cut-out turbidites, or FA4: amalgamated top-cut-out turbidites. In places, depositional patterns depart from this basic organization. In particular, FA1 or FA2 locally constitutes the infill of isolated scour structures marking the pseudo-foreset development. Alternatively, m-thick intervals of FA3 deposits may subordinately contribute to pseudo-channel infills.

\section{Structureless sand and gravel (FA1)}

Beds of structureless sand and gravel mostly consist of massive very coarse to medium sand frequently including granules and small $(<4 \mathrm{~cm})$ pebbles (Figs 8 and 9$)$. They however also include in places restricted volumes of rippled sand (bed tops). A muddy matrix has been noted in some places. At the bed scale, FA1 sand shows rapidly fining-upward trends, in places associated with the appearance of an indistinct planar lamination (Fig. 10; $\mathrm{T}_{\mathrm{A}}$ and $\mathrm{T}_{\mathrm{B}-2}$ subdivisions of Talling et al., 2012), which makes a transition to FA2. Clasts of bedrock lithologies prevail, but a subordinate contribution of flat to contorted intraclasts is observed, for which the source is demonstrably the nearby underlying muddy sand intervals. Intraclast size is typically in the 2 to $6 \mathrm{~cm}$ range, though larger (20 to 30 $\mathrm{cm}$ ) clasts may also be present (inset of Fig. 6 and Fig. 8B). Some very elongated intraclasts might be better described as strips of liquified sand.

Suites of FA1 deposits consist of 20 to $80 \mathrm{~cm}$ thick beds forming 1 to $3 \mathrm{~m}$-thick, fining- and thinning-upward facies sequences (Fig. 10). Beds are definitely erosion-based nearby the bedset boundaries. However, downcurrent, an essentially non-erosional character is evidenced by the preservation of an underlying thin $(<10 \mathrm{~cm})$ interval of rippled medium sand, in places displaying climbing-ripple cross-lamination, which is the $\mathrm{T}_{\mathrm{C}}$ subdivision of the preceding event bed. FA1 deposits are typified by well-defined basal load and flame structures showing thrust and overturned geometries mainly facing downstream (Fig. 6). An upwarddecreasing intensity of this downslopeverging deformation is generally noted in suites of FA1 beds.

Outside the pseudo-channels, FA1 deposits may also be observed forming a single, lenticular, event bed. In this specific 

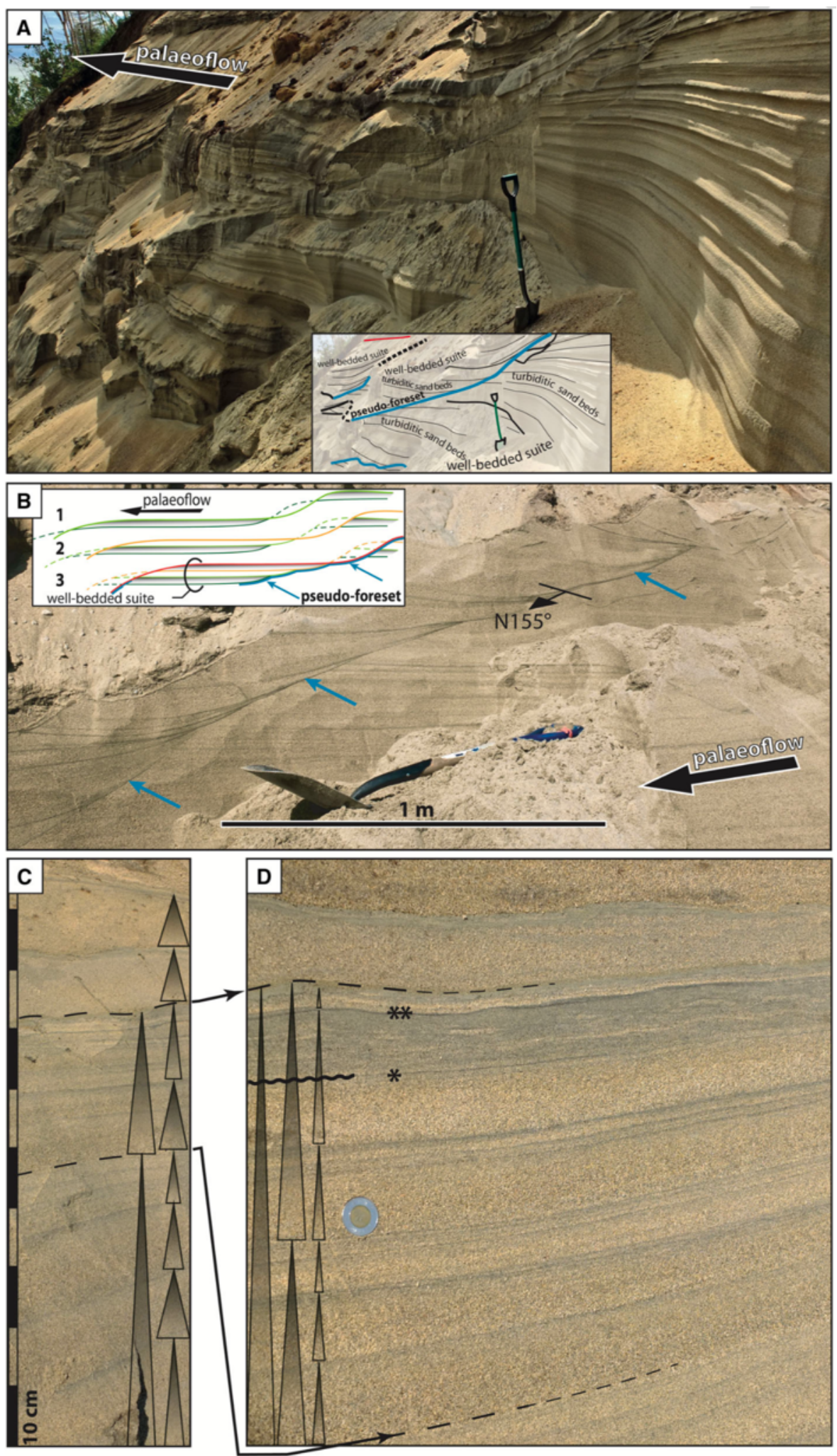

Fig. 7. Well-bedded suites and related depositional structures. (A) Oblique view of two adjacent well-bedded suites bounded by a pseudo-foreset $(1 \mathrm{~m}$ long shovel for scale). Note that the laminae on the right-hand side of the photograph would appear on a cleaned outcrop akin to those illustrated in (D). (B) Detailed view on an upper segment of a pseudo-foreset (location in Fig. 5), corresponding to a superimposition of successive, spoon-shaped, small-scale scours highlighted by dark heavy mineral layers (inset shows time series detailing the formation scenario; see also Slootman and Cartigny, 2020). (C) and (D) the bed stacking pattern in well-bedded suites (FA3), consisting of elementary turbiditic cm- to dm-thick, fining-upward, sand beds (top-cut-out turbidites), which are themselves organized in a hierarchy of fining- and thinning-upward bed sets. $\mathrm{T}_{\mathrm{A}}$ (massive) and $\mathrm{T}_{\mathrm{B}}$ (planar lamination, $\mathrm{T}_{\mathrm{B}-2}$ and/or TВ-1 in the sense of Talling et al., 2012) subdivisions are mainly evidenced, with subordinate rippled fine-grained to muddy sand $\left(\mathrm{T}_{\mathrm{C}}\right)$. Note in $(\mathrm{D})$ some dark heavy mineral layers suggesting lag processes at a within-bed grain-size break $\left(^{*}\right)$ or capping a $\mathrm{T}_{\mathrm{C}}$ subdivision $(* *)$. 
case, related sand tends to onlap directly against a marked, yet isolated, spoon-shaped scour highlighting one of the retrogressive erosion events that has formed the nearby pseudo-foreset (upper-right inset in Fig. 5).

\section{Coarse sand with undulating lamination (FA2)}

Coarse-grained sand beds displaying FA2 are lenticular and have a limited vertical development $(<40 \mathrm{~cm})$ above an erosional basal bounding surface. These sand beds show a faint to well-developed lamination characterized by thick spacing and diffuse contacts (Figs 8C and 9). Undulating and convex-up lamina layouts are ubiquitous, with m-scale wavelengths. Laminae frequently show an upslope-facing mode of deposition. In this case, sand laminae individually backstep and thicken upstreamward when progressively abutting directly against a subvertical scour surface related to either a pseudo-channel margin (Fig. 8C) or a pseudo-foreset (lower segment; Fig. 6, uppermost inset). In places, the undulating lamination follows the irregularities of the underlying erosion surface (Fig. 8B).

\section{Top-cut-out turbidites (FA3)}

Using the nomenclature of Talling et al. (2012) for density-flow deposits, FA3 deposits are best described as top-cut-out turbiditic deposits (Figs 7C and 9). They constitute the bulk of the medium-grained well-bedded suites, within which individual beds are 5 to $20 \mathrm{~cm}$ thick, normally-graded, and structureless to laminated. Sharp basal surfaces are flat, essentially non-erosional, occasionally associated with $\mathrm{cm}$-scale load and/or flame structures. Basal boundaries might be underlined by a 0.5 to $2 \mathrm{~mm}$ thick lamina of heavy minerals. The top-cut-out turbidites usually show a single, fining-up $\mathrm{T}_{\mathrm{A}}$ subdivision (generally medium sand, coarse sand in some cases) or a $\mathrm{T}_{\mathrm{A}}$ and an overlying $\mathrm{T}_{\mathrm{B}}$ subdivisions; the latter being characterized by a thin planar lamination including alternating laminae of clean medium to fine sand and mm-thick darker laminae enriched in heavy mineral grains ( $\mathrm{T}_{\mathrm{B}-2}$ and or $\mathrm{T}_{\mathrm{B}-1}$ subdivisions of Talling et al., 2012). The top part of some rare beds is highlighted by ripple cross-lamination in fine sand forming a $\mathrm{T}_{\mathrm{C}}$ subdivision, corresponding either to: (i) a single train of starved current ripples; (ii) a fining-up alternation of rippled fine sand and $\mathrm{cm}$-thick muddy sand intervals, or, less frequently; (iii) subcritically to critically climbing current ripples. Where the $\mathrm{T}_{\mathrm{C}}$ subdivision is developed, the $\mathrm{T}_{\mathrm{B}}$ subdivision is generally thin to absent, occasionally replaced by a single, mm-thick lamina of concentrated heavy mineral grains. At the m-scale, successive beds are in some cases arranged in second-order bedsets showing an overall fining-up trend marked by the upward-decreasing contribution of $\mathrm{T}_{\mathrm{A}}$ and $\mathrm{T}_{\mathrm{B}}$ subdivisions in favour of the $\mathrm{T}_{\mathrm{C}}$ subdivision (Fig. 7C). Structureless to faintly laminated interlayers of muddy fine sand to sandy mud, 0.5 to $10 \mathrm{~cm}$ thick, occasionally occur. They usually drape the ripple morphologies at the top of the bedset. The thickness of these mud layers is relatively constant along-slope. A few horizons are bioturbated (small vertical burrows). Some rare outsized lonestones have been observed within the sand beds or protruding from the bed top (Fig. 6). Whether they correspond to (ice-rafted?) dropstones and/or to clasts transported by basal flow (Postma et al., 1988) has not been elucidated.

\section{Amalgamated top-cut-out turbidites (FA4)}

Well-bedded suites can also be comprised of medium to coarse sand, showing only diffuse bed contacts and a faint grain-size differentiation (FA4, Fig. 9). FA4 deposits are here described as thin-bedded arrays of superimposed $\mathrm{T}_{\mathrm{A}}$ subdivisions with poorly defined $\mathrm{T}_{\mathrm{B}-1}$ subdivisions (note, however, that FA4 might also be alternatively understood as thick sand beds characterized by a spaced planar lamination, the Тв-3 subdivision of Talling et al., 2012). This somewhat enigmatic depositional facies has a modal grain size typically in the 300 to $1400 \mu \mathrm{m}$ range (predominantly medium to coarse, moderately sorted sand; Fig. 11), is finer than FA1 and FA2 sands and generally coarser than FA3 deposits. Thin muddier interbeds with diffuse contacts have been noted in places but no other associated sedimentary structures have been observed. The distinction between FA3 and FA4 deposits can be ambiguous in places, especially where the degree of bed amalgamation is intermediate in transitional deposits.

Facies transitions in pseudo-channels and isolated scour fills

In pseudo-channel infills, coarse sand with undulating lamination (FA2) generally overlies or interfingers with structureless sand and gravel (FA1), forming larger-scale 


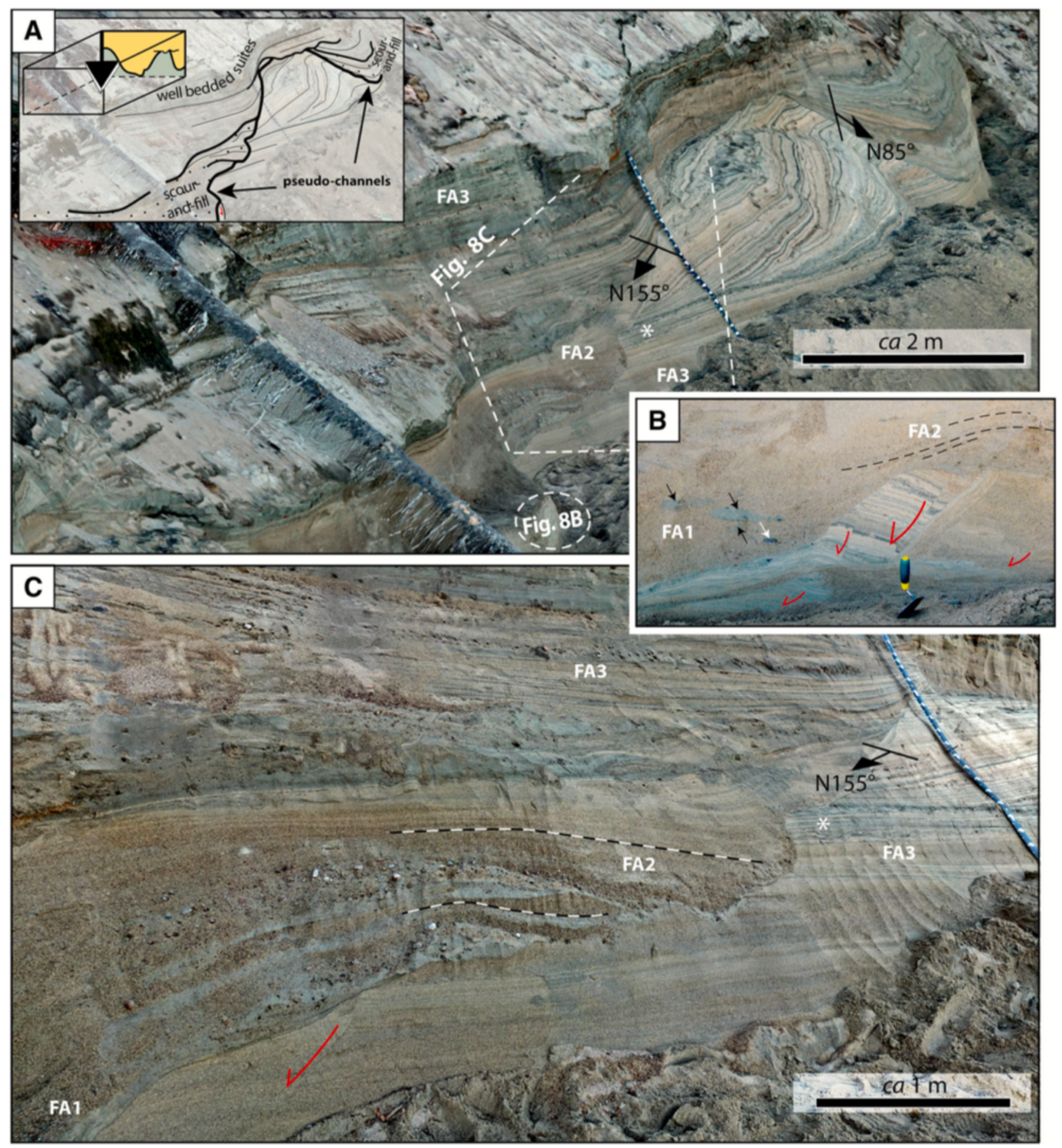

Fig. 8. Pseudo-channels and related deposits (see location in Fig. 5). (A) Oblique plan view drone image, palaeocurrent towards the observer; coarse brown sand prevails in pseudo-channel fills, while lighter sand characterizes the underlying truncated deposits (dip orientations of pseudo-channel margins are noted). (B) Structureless coarse sand containing pebbles (FA1, lower part; black arrows: rip-up mud clasts; white arrow: basement clast) and passing to faintly laminated (FA2, upper part, dashed lines). FA1 and FA2 deposits onlap translated sand masses (including bioturbation), the original position of which was found $2 \mathrm{~m}$ higher and $4 \mathrm{~m}$ upslope (white stars in A and C). These translated sand masses underline the erosion margin of the pseudo-channel (see also Fig. 5). (C) Coarse to pebbly sand that shows an assemblage of convex-up to undulating laminae (FA2). Dashed blackwhite lines highlight individual laminae that thicken upstreamward. Red arrows indicate small extensional faults. 

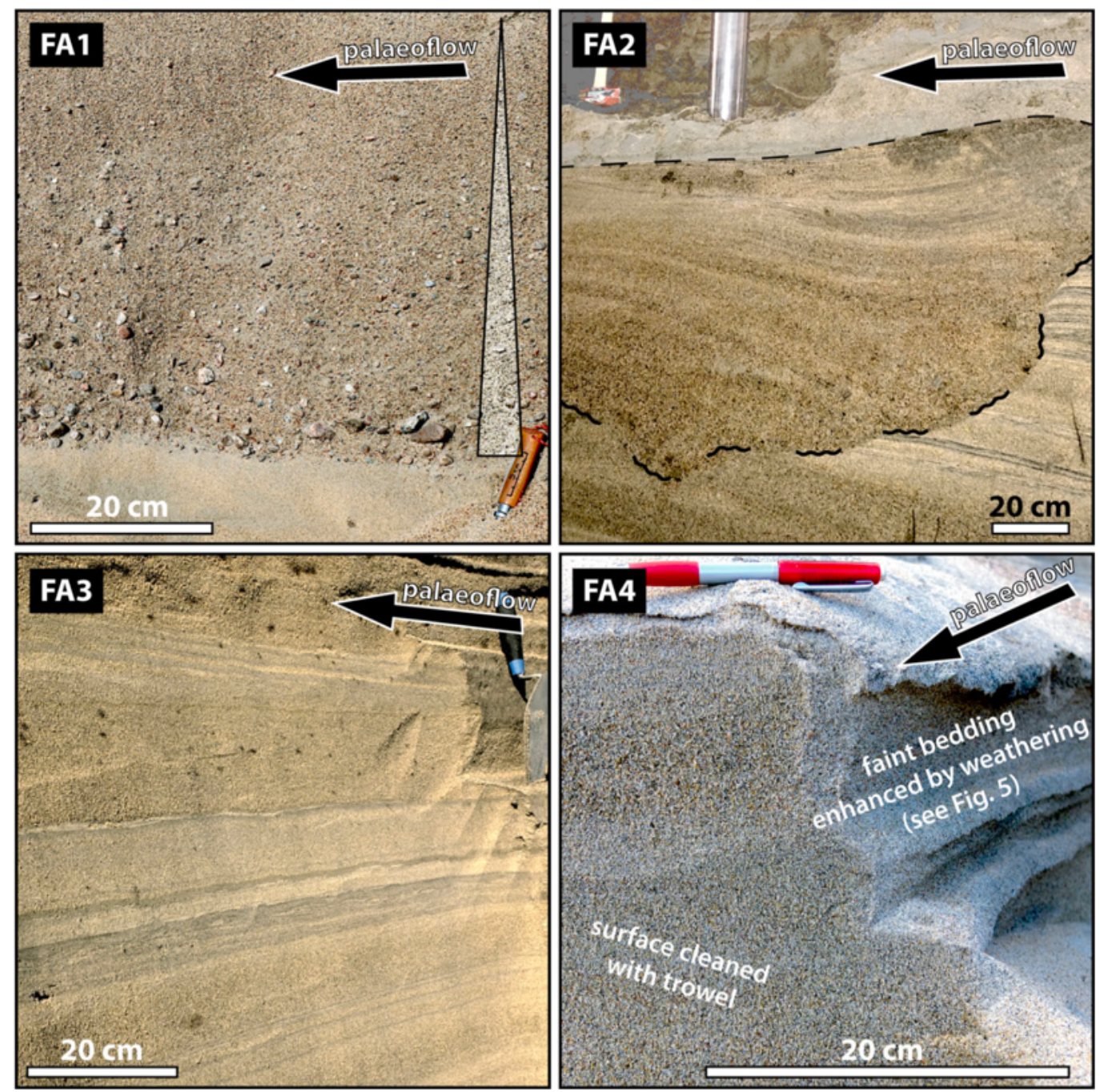

Fig. 9. Archetypal lithofacies and facies associations. FA1: Structureless sand and gravel (see also Figs. 8B and 10); FA2: Coarse sand with undulating lamination (see also Fig. 8C); FA3: Top-cut-out turbidites (see also Fig 7C and D); FA4: Amalgamated top-cut-out turbidites (see also Fig. 10). FA1 and FA2 characterize the pseudo-channel infills while FA3 and FA4 typify the well-bedded suites, which however also include in places subordinate FA1 and/or FA2 occurrences (Fig. 5; Table 2). FA1 and FA2 deposits are linked to cyclic-step instabilities in a stratified turbidity currents (peak- to waning-flow conditions); FA3 and FA4 deposits are interpreted as the result of expanded turbidity currents. See Discussion and Figs 15 and 16. 


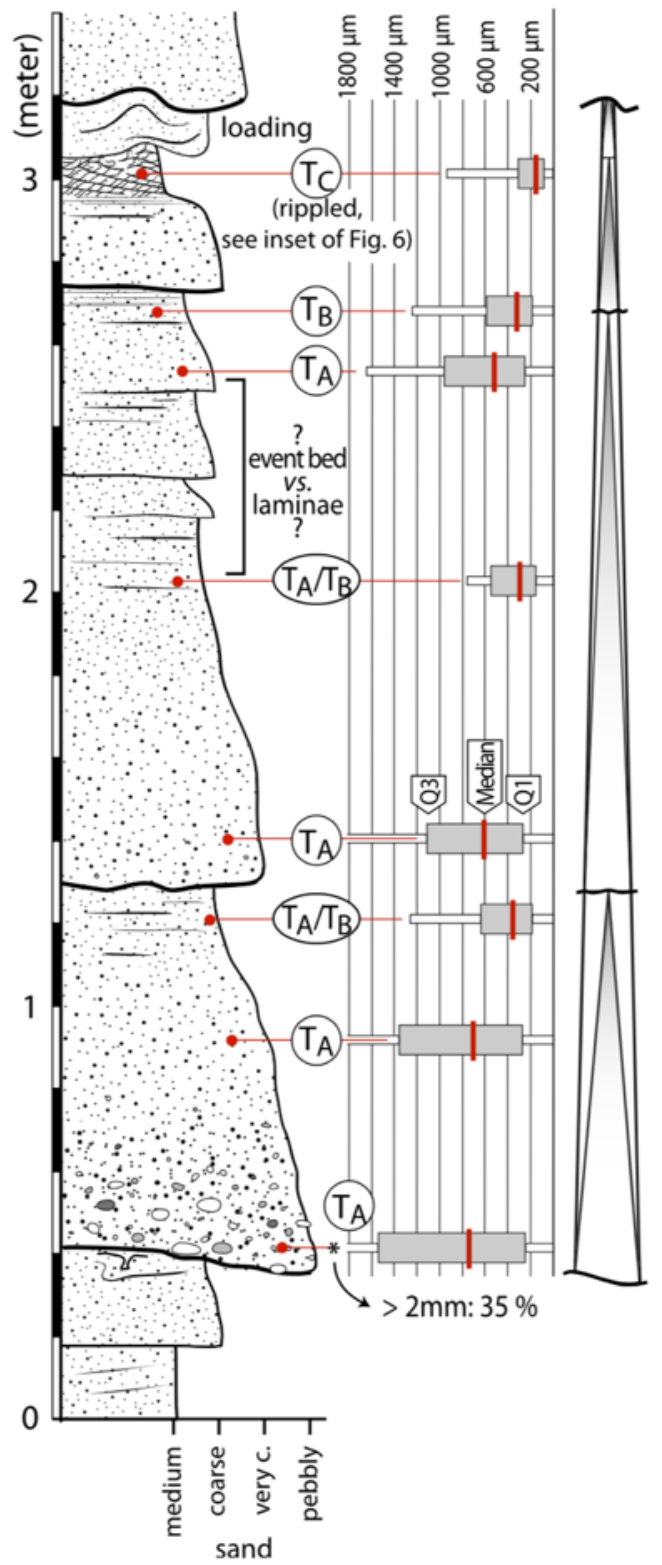

Fig. 10. Layout of eight sand samples collected in thick turbiditic beds (FA1; location in Fig. 6). Note that discriminating sand beds from thick laminae may be challenging (interval 2 to $2.6 \mathrm{~m}$ ). A subdivision in three fining-up turbidites is proposed, which further shows an overall finingup trend, culminating with a well-developed $\mathrm{T}_{\mathrm{C}}$ subdivision showing climbing-ripple cross-lamination (see inset in Fig. 6). Only the basal sample has a significant coarse fraction $>2 \mathrm{~mm}$ ( $35 \%$ in weight).

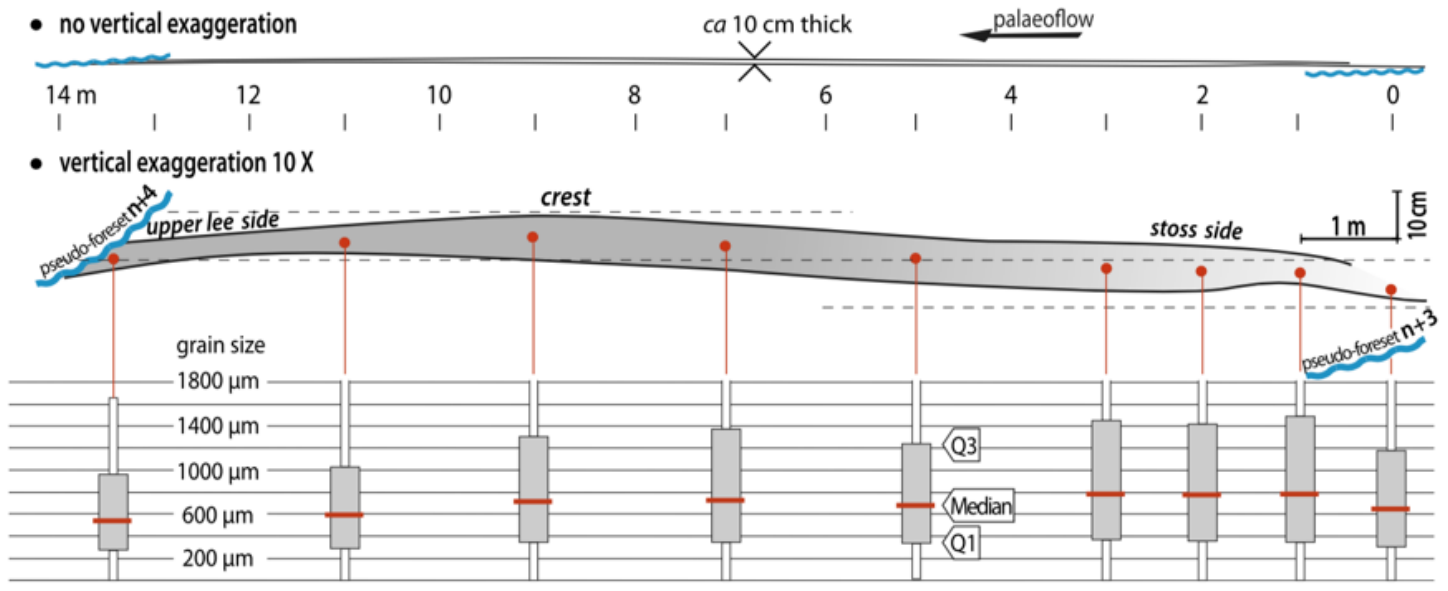

Fig. 11. Layout of nine sand samples collected along a single $c a 10 \mathrm{~cm}$ thick turbidite from a well-bedded suite (FA4, essentially a $\mathrm{T}_{\mathrm{A}}$ subdivision) located between pseudo-foresets $\mathrm{n}+3$ and $\mathrm{n}+4$ of Fig. 3C (see also location in Fig. 5). Samples show a subtle downcurrent fining trend along the stoss side, which becomes clearer beyond the bedform crest along the upper lee side. Note the subhorizontal bed conformation, which appears as a backstepping bed only if a vertical exaggeration is applied (see also Fig. 12). 
fining- and thinning-upward motifs. FA1 here represents significant sand volumes deposited within a 0 to $15 \mathrm{~m}$ range downstream of a pseudo-foreset. In contrast, FA2 corresponds to spatially restricted lenticular bodies specifically onlapping the erosional bedset boundary and wedging out rapidly a few metres downstream (Fig. 8C). In addition, while FA1 deposits may grade upwards into FA2, basal bed contacts of FA1 sand are most often sharp, more clearly erosional when approaching a bedset boundary. Outside the pseudo-channels, FA2 deposits may also constitute the only infill of some isolated scour structures along the pseudo-foresets, without an intervening, previously deposited, underlying body of FA1 deposits (e.g., uppermost inset of Fig. 6).

\section{Facies transitions related to well-bedded suites}

Both vertical and along-slope transitions are observed within and between FA3 and FA4 deposits. From the base to the top of the delta slope succession, a gradual evolution is noted in well-bedded suites. In the lower part of the succession, interbeds of muddy sand tend to be thicker and more frequent. Dark laminations concentrating heavy mineral grains and ripples ( $\mathrm{T}_{\mathrm{C}}$ subdivision) are the rule. As a consequence, stratigraphically lower depositional facies are mostly ascribed to FA3, while FA4 deposits are subordinate. In contrast, bed amalgamation prevails and FA4 deposits are predominant in the wellbedded suites characterizing the upper part of the delta slope succession deposited in shallower water. In intermediate positions, well-bedded suites with a poorly developed bed amalgamation appear as transitional between FA3 and FA4 deposits.

Along-dip variations are also noted in FA3 deposits. Upstreamward, when approaching the pseudo-foreset against which they are onlapping, FA3 deposits may have notable dips and show a paraconformable layout (Figs 5 to 7 ). Here, the $\mathrm{T}_{\mathrm{B}}$ subdivisions tend to be thinner, $\mathrm{T}_{\mathrm{C}}$ subdivisions are virtually absent and the frequent superimposition of beds with only a $\mathrm{T}_{\mathrm{A}}$ subdivision is noted (FA3/FA4 transitional facies). Basal bed contacts remain essentially paraconformable up to the onlapping contact with the pseudo-foreset, yet often evidenced by several mm-thick heavy mineral concentrations (Fig. 7B). Conversely, moving downstream toward the truncation beneath the next pseudo-foreset downslope, sand beds show an overall fining trend, in tandem with better developed $\mathrm{T}_{\mathrm{C}}$ subdivisions and thicker $\mathrm{T}_{\mathrm{B}}$ subdivisions. Occasional coarse-grained $\mathrm{T}_{\mathrm{A}}$ subdivisions might still be observed. A similar fining trend is also noted in FA4 deposits. Along an individual bed, grain-size analysis shows a horizontal fining trend in the palaeoflow direction, together with a slightly better sorting (Fig. 11). This trend is best expressed beyond the crest.

\section{Interpretation}

Cross-stratal pattern

Given that palaeocurrents and downslope orientation are well identified along the Portneuf-Forestville delta slope (Dietrich et al., 2017b), the cross-stratal pattern, and more specifically the well-bedded suites and intervening pseudo-foresets, suggest the aggradation of regularly-spaced, asymmetrical bedforms characterized by an upslope direction of migration (Fig. 12; Cartigny et al., 2011; Slootman and Cartigny, 2020). Along these bedform trains, subhorizontal to slightly upslope-dipping stoss sides alternate with steeper, downslope-dipping lee sides. Bedform stoss sides and uppermost lee sides are mostly depositional as indicated by ubiquitous paraconformable inter-bed contacts. In contrast, the lower segment of the lee sides was locus of preferential erosion or sediment reworking as indicated by repetitive truncations (scour geometries) and heavy mineral lags evidencing winnowing processes (Fig. 7B, see also insets in Figs 5 and 6). The first-order cross-stratal pattern is thus fully compatible with that of an up-slope migrating train of supercritical-flow bedforms, either asymmetrical cyclic steps or antidunes (Fildani et al., 2006; Spinewine et al., 2009; Cartigny et al., 2011; Hughes Clarke, 2016; Vellinga et al., 2017). Well-bedded suites can be compared to the aggradational backstepping beds observed in architectural models (e.g. Vellinga et al., 2018) and inferred from stratigraphies reconstructed from repeat swath bathymetry (e.g. Hage et al., 2018; Vendettuoli et al., 2019; Normandeau et al., 2020). It should be noted, however, that the backstepping conformation might be subtle without vertical exaggeration (Figs 5 and 12). Pseudo-channel infills may correspond to amalgamated scour fills identified in reconstructed stratigraphies (Hage et al. 2018; see also Englert et al., this issue, fig. 9).

\section{Pseudo-foresets versus delta-slope clinoforms}


Pseudo-foresets, individually formed by the superimposition of successive erosion surfaces, are not representative of any depositional geometries or bedforms [Dietrich et al., 2016; composite erosion surfaces of Slootman and Cartigny (2020)]. Pseudoforesets correspond to retrogressive climbing planes dipping basinward, i.e., downslope, in a symmetrical way to the upslope-dipping plane separating two successive ripple (Ashley et al., 1982) or megaripple (Ghienne et al., 2010) sets within a more usual climbing assemblage (Fig. 12). A single well-bedded suite in between two successive pseudoforesets might be referred to as a pseudobed (McKee, 1965) or a translatent strata sensu lato (Hunter, 1977). Deposition of spatially successive well-bedded suites separated by intervening pseudo-foresets is, however, regarded as synchronous (Figs 5 and 12; Vellinga et al., 2018; Slootman and Cartigny, 2020).

As a consequence, the original but generally non-preserved bedform lee sides were steeper than the resulting pseudoforesets amalgamating several upslopemigrating erosion surfaces (inset of Fig. 7B; see also Slootman and Cartigny, 2020, for a full description). Conversely, "averaged" clinoformal slopes were lying at a dip notably lower than that of the pseudo-foreset $\left(6^{\circ}\right.$ versus $20^{\circ}$ in Fig. 5; Fig. 12). A reconstruction of the stepped profile of the delta foresets requires connecting successive segments preserved from one well-bedded suite to the next one -in the downstream sensecrossing the intervening pseudo-foresets (for instance, the yellow and orange horizons in Fig. 12).

\section{Depositional processes}

"Turbiditic" facies sequences and subdivisions at the bed scale, occurrence of sheared flame structures and internal erosion events indicated by large intraformational clasts are facies-based elements that favour a cyclicstep interpretation (Postma et al., 2014; Ventra et al., 2015; Dietrich et al., 2016; Lang et al., 2017). However, amongst the four facies associations, only structureless sand and gravel of FA1 is really diagnostic of depositional conditions linked to a cyclic-step instability (Cartigny et al., 2011; Postma and Cartigny, 2014; Slootman and Cartigny, 2020). Indeed, FA1 deposits (Fig. 9) characterize depositional processes linked to an active hydraulic jump in the troughs of a train of cyclic steps as shown by: (i) structureless sand trapping the coarsest grain size; (ii) minimal erosion along some segments of their basal bed contacts; (iii) their frequent association with liquefaction structures (Fig. 6, middle part); and (iv) lenticular sand bodies originating from deposition focused in pseudo-channels or isolated scours nearby a pseudo-foreset (Postma et al., 2009, 2014; Lang et al., 2017; Massari, 2017; Ono et al., in press). FA1 deposition is interpreted as the result of highdensity stratified flows, with a basal layer characterized by a cyclic-step instability (Postma and Cartigny, 2014). Occurrence of gravitational deformation structures in leeside contexts (Fig. 6, right-hand side) indicates the recurrent formation of out-ofequilibrium scour surfaces tied to deep truncations, illustrating the efficiency of the erosion processes in the bedform troughs of cyclic steps. Instability was associated with fluidization, as shown by liquefaction structures and liquefied sand intraclasts, suggesting breaching processes and shear dilatancy along a steep slope under fast flows (Cartigny et al., 2014; and references therein). Volumes of fluidized sand originating from the lee side, driven downslope by the overriding supercritical dense layer, may have contributed in places to active deposition over the next stoss side as a liquefied flow. After mixing, part of the fluidized sand may have been incorporated in the supercritical dense basal layer.

In FA2 deposits (Fig. 9), thick and undulating laminae showing an upslopefacing accretionary pattern are interpreted as the result of transient antidune depositional conditions characterizing the basal layer of a supercritical, high-density, stratified flow. Preservation of convex laminae suggests high-aggradation rates (Cartigny et al., 2014). Such short-wavelength, m-scale antidune deposits superimpose hydraulicjumps deposits and are restricted to bedform troughs, not expanding along the adjoining stoss side. Interfingered with, or deposited above FA1 sand, antidune deposits of FA2 reflect temporal flow pulsations, fluctuations of the flow interface (Yokokawa et al., 2009) and/or short-term depositional stages during or at the end of a flow event and without a concomitant hydraulic jump.

Thinning-up and fining-up trends in pseudo-channel infills are evidenced within FA1 successions (Fig. 10) and/or by FA1-FA2 successions (Fig. 6). They are interpreted either as the result of a retreating lee side and 
Table 2. Facies associations from the upper delta-slope sands of the late Quaternary Portneuf-Forestville case study.

\begin{tabular}{|c|c|c|c|c|c|}
\hline $\begin{array}{c}\text { Facies Association and } \\
\text { lithologies }\end{array}$ & $\begin{array}{c}\text { Stratal patterns } \\
\text { (Figs 5-8, 12) }\end{array}$ & $\begin{array}{c}\text { Bed configuration } \\
\text { (Figs 7-9) }\end{array}$ & $\begin{array}{c}\text { Subordinate features } \\
\text { (Fig. 6) }\end{array}$ & $\begin{array}{c}\text { Deformation } \\
\text { structures (Fig. 6) }\end{array}$ & $\begin{array}{l}\text { Interpretation } \\
\text { (Figs } 15 \text { and 16) }\end{array}$ \\
\hline $\begin{array}{l}\text { FA1 } \\
\text { Structureless sand and gravel } \\
\text { (bedrock clasts and intraclasts) }\end{array}$ & $\begin{array}{l}\text { Scour fills constituting } \\
\text { pseudo-channels; less } \\
\text { frequently, in isolated } \\
\text { spoon-shaped scours along } \\
\text { the pseudo-foresets }\end{array}$ & $\begin{array}{l}20-80 \mathrm{~cm} \text { thick, fining-up, } \\
\text { structureless beds; } \\
\text { Isolated lenticular bed } \\
\text { and/or thinning upward } \\
\text { facies sequences; basal } \\
\text { bounding surface is } \\
\text { erosional close to pseudo- } \\
\text { foresets }\end{array}$ & $\begin{array}{l}\text { Contorted rip-up mud and } \\
\text { sand clasts; strips of } \\
\text { liquefied sand; a muddy } \\
\text { matrix in places; } \\
\text { Grade upward into indistinct } \\
\text { planar lamination and/or } \\
\text { rippled sand }\end{array}$ & $\begin{array}{l}\text { Intense basal loading } \\
\text { showing dm-scale to } \mathrm{m} \text { - } \\
\text { scale load and flame } \\
\text { structures; shear } \\
\text { deformation structures, } \\
\text { mainly oriented } \\
\text { downcurrent }\end{array}$ & $\begin{array}{l}\text { High-density supercritical currents } \\
\text { (intervening low-density currents, } \\
\text { waning-flow conditions); } \\
\text { hydraulic jump deposits from } \\
\text { pulsating (thinning-up sequences) } \\
\text { cyclic steps or from short-lived } \\
\text { events (isolated scour) }\end{array}$ \\
\hline $\begin{array}{l}\text { FA2 } \\
\text { Coarse sand with undulating } \\
\text { lamination }\end{array}$ & $\begin{array}{l}\text { Onlapping the bedset } \\
\text { boundaries: either overlying } \\
\text { FA1 deposits in pseudo- } \\
\text { channel infills or in isolated } \\
\text { spoon-shaped scours along } \\
\text { pseudo-foreset }\end{array}$ & $\begin{array}{l}\text { Erosion-based, } 10-40 \mathrm{~cm} \\
\text { thick, fining-up, lenticular } \\
\text { sand beds; m-scale, convex } \\
\text { to undulating laminae } \\
\text { including upstream-facing } \\
\text { cross-strata }\end{array}$ & - & - & $\begin{array}{l}\text { Short-wavelength antidune } \\
\text { deposits from the dense basal } \\
\text { layer of high-density turbidity } \\
\text { currents; succeeding to a cyclic- } \\
\text { step instability }\end{array}$ \\
\hline $\begin{array}{l}\text { FA3 } \\
\text { Top-cut-out turbidites } \\
\text { (coarse to fine sand) }\end{array}$ & $\begin{array}{l}\text { In well-bedded suites, } \\
\text { with onlaps or quasi-draping } \\
\text { geometries on pseudo- } \\
\text { foresets; } \\
\text { less frequently, limited } \\
\text { contribution to pseudo- } \\
\text { channel infills }\end{array}$ & $\begin{array}{l}5-20 \mathrm{~cm} \text { thick, fining-up, } \\
\text { aggrading and/or } \\
\text { backstepping beds with a } \\
\text { conformable or slightly } \\
\text { erosional lower surface; } \\
\text { massive to planar laminated } \\
\text { and/or rippled sand (rare } \\
0.5-10 \mathrm{~cm} \text { thick mud drapes) }\end{array}$ & $\begin{array}{l}\text { A grain-size break bounding } \\
\text { the underlying massive or } \\
\text { planar laminated sand from } \\
\text { the overlying rippled sand; } \\
\text { starved to climbing ripples; } \\
\text { occasional bioturbation } \\
\text { (burrows) }\end{array}$ & $\begin{array}{l}\text { Cm-sized basal load and } \\
\text { flame structures; } \\
\text { Extensional step } \\
\text { fractures close to } \\
\text { erosional bedset } \\
\text { boundaries }\end{array}$ & $\begin{array}{l}\text { Deposition from expanded high- } \\
\text { density turbidity currents, } \\
\text { superimposing cyclically-stepped } \\
\text { morphologies, possibly under } \\
\text { long-wavelength antidunal flow } \\
\text { conditions. Low-density currents } \\
\text { during waning-flow conditions }\end{array}$ \\
\hline $\begin{array}{l}\text { FA4 } \\
\text { Amalgamated top-cut-out } \\
\text { turbidites } \\
\text { (coarse to medium sand) } \\
\text { Fig. } 11\end{array}$ & $\begin{array}{l}\text { In well-bedded suites, } \\
\text { with onlaps or quasi draping } \\
\text { geometries on pseudo- } \\
\text { foresets; grade downcurrent } \\
\text { into FA3 }\end{array}$ & $\begin{array}{l}3-10 \mathrm{~cm} \text { thick sand layers } \\
\text { showing diffuse contacts; } \\
\text { discriminating beds and } \\
\text { spaced planar lamination } \\
\text { can be ambiguous }\end{array}$ & - & - & $\begin{array}{l}\text { The same as for FA3, yet } \\
\text { preferentially associated with } \\
\text { shallower segments of the delta } \\
\text { slope }\end{array}$ \\
\hline
\end{tabular}




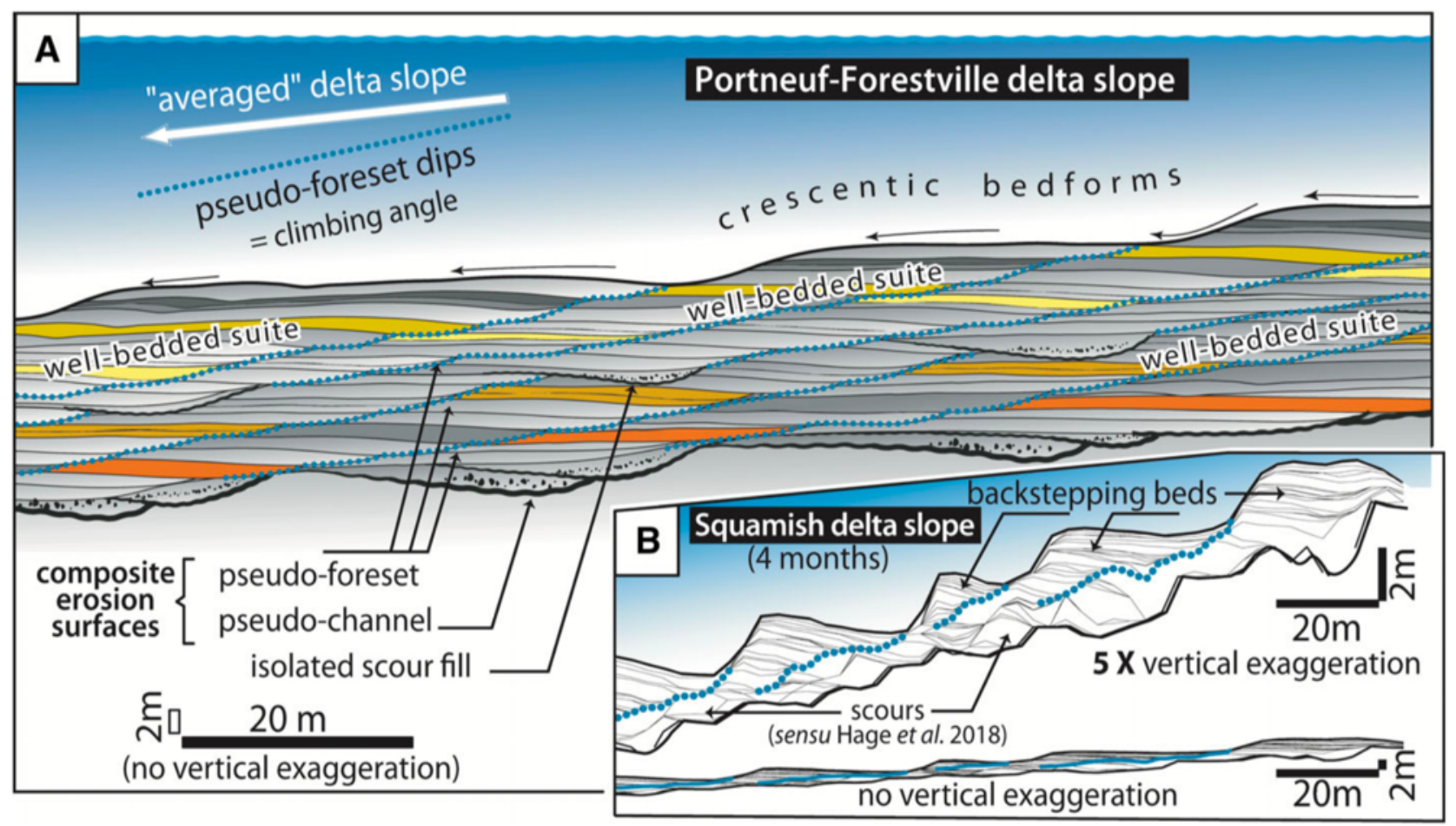

Fig. 12. Stratal patterns in proglacial delta-slope sands involving cyclic steps. (A) Conceptual model showing the relation of well-bedded suites to aggrading, asymmetrical bedforms migrating upslope along the fossil upper delta slope of the Portneuf-Forestville complex. Grey horizons represent the layout of turbidites (laminae not shown), four of which have been coloured to highlight discontinuous, yet synchronous layers. Resulting well-bedded suites are interrupted by composite erosion surfaces in the sense of Slootman and Cartigny (2020), here referred to as pseudoforesets (blue dotted lines) and representing retrogressive climbing planes showing ca $12^{\circ}$ dips (10 to $20^{\circ}$ in Fig. 3). The original, "averaged", delta slope, with significant lesser dips $\left(c a 6^{\circ}\right)$, is poorly identifiable from this stratal pattern (see also grey dotted lines in Fig. 5). (B) For comparison, the stratigraphy reconstructed from a 4-month repeat swath bathymetry survey in the Squamish delta (redrawn from Hage et al., 2018). Backstepping beds evidenced owing to vertical exaggeration are analogous to the here-described well-bedded suites (see Fig. 11). Pseudo-foreset geometries are here also identifiable (blue dotted lines). In both cases (A and B), pseudo-channel/scour infills prevail in the lower part of the succession. 
associated retrogressive hydraulic jumps and depletive flow conditions (in the sense of Kneller and Branney, 1995) over the stoss side, or as the signature of overall waningflow conditions (Postma et al., 2014), or a combination of both. In places, flow unsteadiness and convincing waning-flow conditions are best highlighted by an interval of rippled sand implying deposition under relatively long-lived, subcritical, low-density flow conditions (Talling et al., 2012). Waningflow conditions immediately succeeding a cyclic-step instability have been monitored along the modern Squamish delta slope (Hughes Clarke, 2016). There, a single turbidity current was responsible for $\sim 1.5 \mathrm{~m}$ of upslope migration of the lee sides and for deposition of a 0.25 to $0.5 \mathrm{~m}$ thick deposit along the stoss sides (Hage et al., 2018). These values are in line with the signature of a singular event cutting an isolated scour and depositing a fining-up turbidite displaying FA1 deposits (Fig. 5).

Medium to coarse-grained FA3 and FA4 deposits are interpreted mainly as highdensity turbidites based on grain size, prevailing $\mathrm{T}_{\mathrm{A}}$ (massive) and $\mathrm{T}_{\mathrm{B}}$ (planar lamination) subdivisions, and occurrences of a clear grain-size break and bypass horizon separating the underlying $\mathrm{T}_{\mathrm{A}}$ and $\mathrm{T}_{\mathrm{B}}$ subdivisions from an overlying, rippled $\mathrm{T}_{\mathrm{C}}$ subdivision (Fig. $7 \mathrm{C}$ and $\mathrm{D}$; Talling et al., 2012). $\mathrm{T}_{\mathrm{C}}$ subdivisions in FA3 highlight the contribution of recurrent low-density turbidity currents over the delta slope as far as the well-bedded suites are concerned. Topcut-out turbidites are sometimes acknowledged as representatives of the depositional conditions typifying the stoss sides of cyclic steps (Cartigny et al., 2011; Postma and Cartigny, 2014; Postma et al., 2014).

However, considering the well-bedded suites of the Portneuf-Forestville delta slope, some specificities of the top-cut-out turbidites question the generalization of a cyclic-step model applied to the overall depositional succession. Recurrent rippled sand, the absence of hydraulic jump deposits and the quasi-draping conformation of some of the lee-side beds - passing without any internal facies change or notable bed thickness change to the stoss-side bed- are sedimentary features poorly compatible with a depositional model invoking only cyclic steps. They rather suggest that a variety of depositional regimes (subcritical versus supercritical; low-density and high-density flows; erosional versus depositional) occurred through time in the Portneuf-Forestville delta-slope depositional system. In this scheme, there is no direct relationship between the resulting bedform geometry and a particular flow type, several flow types contributing ultimately to the building of the overall stratigraphic architecture yet including undisputable cyclic-step features. The understanding of the associated flow variations thus requires further consideration (see the Discussion) in order to define: (i) which stratal patterns described from the Portneuf-Forestville delta-slope deposits precisely relate to cyclic steps, potentially with internal flow pulsations (Yokokawa et al., 2009; Slootman and Cartigny, 2020); and (ii) which stratal patterns relate to alternative flow conditions, i.e., not necessarily including cyclic-step instabilities, yet superimposing a preexisting cyclically-stepped delta slope (see also Slootman et al., 2019).

\section{THE SOUTHWIND FJORD CASE STUDY}

\section{Description}

\section{Crescentic bedforms}

The Southwind Fjord delta slope mainly consists of a $2500 \mathrm{~m}$ long, 80 to $125 \mathrm{~m}$ wide submarine channel in which crescentic bedforms are observed throughout (Figs 2B and 13). On the upper delta slope, where the gradient is about $6^{\circ}$, wavelengths of the crescentic bedforms range mainly from 10 to $20 \mathrm{~m}$. They gradually increase toward the lower parts of the channel, ranging from 50 to $80 \mathrm{~m}$, as the slope becomes gentler ( 1 to $3^{\circ}$; Fig. 13). Locally, the wavelength decreases in areas of greater gradients. Bedforms show amplitudes of 1 to $2 \mathrm{~m}$ and are asymmetric. Lee sides dip 7 to $22^{\circ}$ and stoss sides display subtle reverse $\left(-1^{\circ}\right)$ dips relative to the overall delta slope. Beyond the crest, bedforms show a gently dipping configuration, then plunging abruptly into a distinctive trough. At the mouth of the channel, at water depths greater than $120 \mathrm{~m}$, bedforms lose their crescentic shape and become more sinuous but with essentially unchanged wavelengths.

Swath bathymetry datasets collected in October 2013 and October 2014 in the lower part of the channel are compared to assess the movement of the crescentic bedforms (Fig. 13B). Bedforms migrated 40 to 

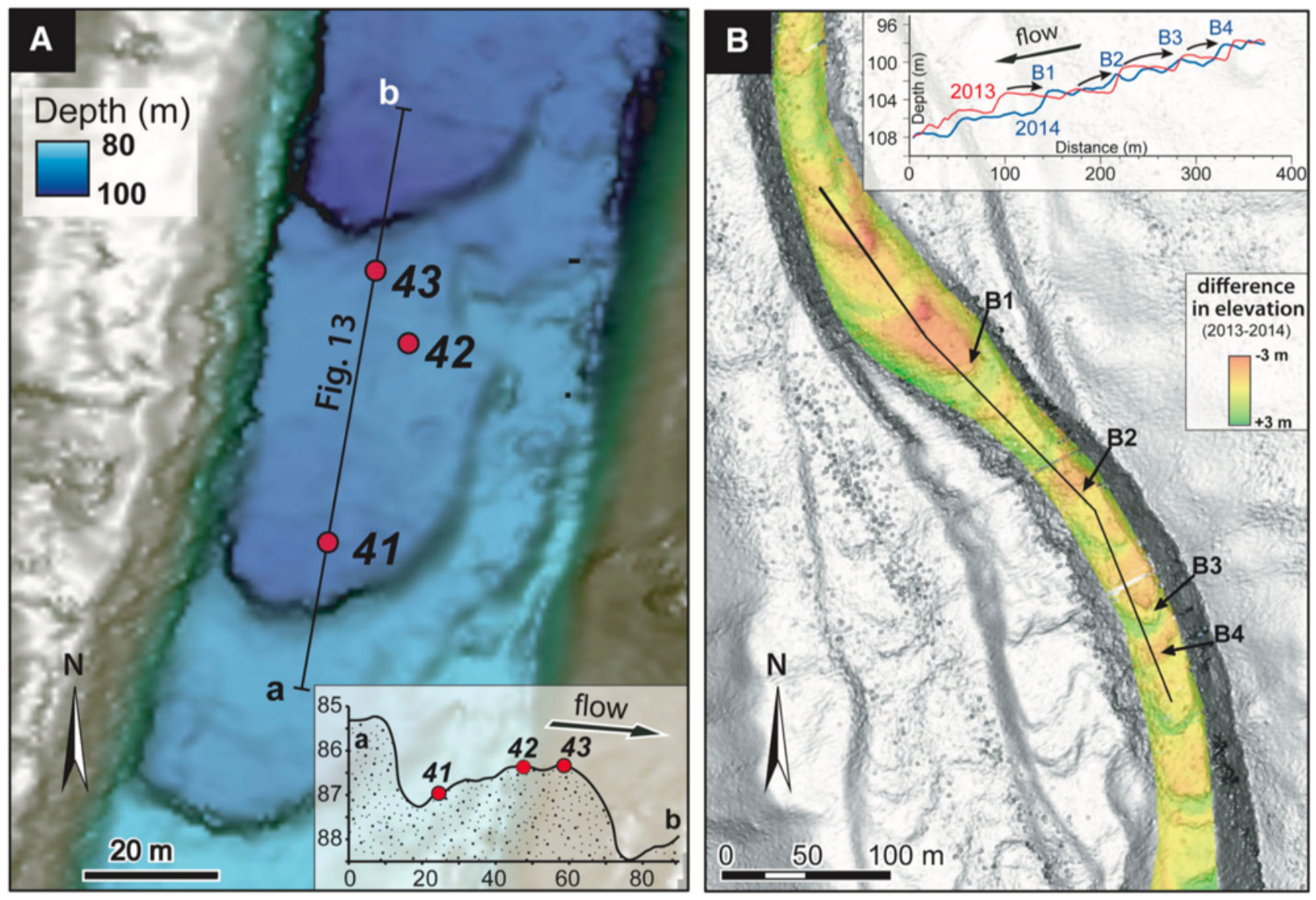

Fig. 13. Cyclic steps observed in a submarine channel of a modern turbiditic system (Southwind Fjord delta slope, Baffin Island). (A) Location of IKU grabs on a single cyclic step (location in Fig. 2B). (B) Difference in elevation between two surveys (2013 and 2014, location in Fig. 2B) in the lower part of the channel system illustrating erosion of the lee side and the deposition on the stoss side of four active bedforms labeled B1 to B4. This erosional/depositional pattern leads to the upslope migration of the crescentic bedforms, interpreted as cyclic steps. 
$60 \mathrm{~m}$ upslope with up to $3 \mathrm{~m}$ of retrogressive erosion on the lee side and a maximum of $3 \mathrm{~m}$ deposition on the stoss side. These changes on the bedforms are likely formed by numerous flows occurring during the late spring and summer and, most probably, are not the result of one individual flow. Where the grab samples were collected (Fig. 13A), the comparison with the 2018 data (Fig. 2B) does not allow observation of the migration of the bedforms since they have been completely reorganized during that 4-year period of no observation.

In 2013, crescentic bedforms in the channel appeared to be constrained by a sidewall failure (Fig. 2B). Nonetheless, they appeared to be tightly spaced (20 to $30 \mathrm{~m}$ wavelength), whereas in 2018, they had longer wavelength in the 30 to $75 \mathrm{~m}$ range and the sidewall failure deposit was completely evacuated or reworked in the channel (Fig. 2B). These changes on the seabed morphology are attributed to the remobilization of sediment during turbidity currents and the upslope migration of the crescentic bedforms over time.

\section{Lithofacies}

Three large grab samples were collected over a single bedform, near the trough, on the stoss and on the crest (Fig. 14, samples 41, 42 and 43, respectively). The sedimentary structures along the $40 \mathrm{~cm}$ deep grabs reveal contrasting depositional signatures between the samples. Several turbidites are observed, which cannot be correlated with each other (note that the upper boundary of each grab might not precisely correspond to the sediment-water interface). Sample 41 comprises three distinct event beds. Sample 42 shows one main bed corresponding to amalgamated event beds, followed by two thin beds. Sample 43 captured the top of one bed and 2 to 3 overlying event beds. The sampling method also allows identifying internal sedimentary structures.

At the downstream end of the trough (sample 41), the bottommost turbidite is $>24$ $\mathrm{cm}$ in thickness (its base was not sampled). It consists of poorly sorted gravelly sand fining upwards to coarse sand and including small muddy rip-up clasts. This first event bed is topped with a thin $(\mathrm{ca} 2 \mathrm{~cm})$, finer-grained, rippled interval. The overlying bed displays a sharp base and is $10 \mathrm{~cm}$ thick. It consists of fining-upward coarse to medium sand, with poorly developed parallel lamination in its uppermost part. The uppermost bed, $13 \mathrm{~cm}$ thick, is similar to the lower one. It consists of basal coarse sand and gravel with sheared flame structures and muddy, 1 to $5 \mathrm{~cm}$ long rip-up clasts. In comparison with the Portneuf-Forestville case study, both the bottom- and uppermost event beds would be straightforwardly classified as FA1 deposits.

In sample 42, taken as a representative of deposits along the bedform stoss side, a single, $>40 \mathrm{~cm}$ thick interval forms most of the grab. In the lower half of the grab, this interval consists of homogenous ( $\mathrm{T}_{\mathrm{A}}$ subdivision) to faintly parallel laminated $\left(\mathrm{T}_{\mathrm{B}}\right)$ medium to coarse moderately sorted sand. Upward, a distinctive $15 \mathrm{~cm}$ thick interval with prevailing parallel laminated fine sand $\left(\mathrm{T}_{\mathrm{B}}\right.$, subordinate $\mathrm{T}_{\mathrm{A}} / \mathrm{T}_{\mathrm{B}}$ ) is observed. Here, the lamination is enhanced by dark, heavy minerals. It then grades to ripplelaminated sand $\left(\mathrm{T}_{\mathrm{C}}\right)$ over $3 \mathrm{~cm}$. Subtle grainsize variations indicate that this interval likely corresponds to an amalgamation of event beds. Two thin (less than $3 \mathrm{~cm}$ thick) event beds are preserved at the topmost part of the grab, consisting of laminated, possibly rippled sand and mud caps. The lower one shows a distinctive double mud cap. Bioturbation was evident upon sampling in these upper mud caps, which showed in addition the presence of worms. The latter deposits have essentially draped the ripple morphology inherited from the underlying bed top.

At the crest (sample 43), above a sharp base truncating a $>10 \mathrm{~cm}$ thick interval of rippled sand, two event beds show characteristics similar to the stoss-side deposits regarding the grain size, with homogenous to faintly laminated sand $\left(\mathrm{T}_{\mathrm{A}}\right.$ or $\left.\mathrm{T}_{\mathrm{B}}\right)$ followed by a well-developed ripplelaminated sand interval $\left(\mathrm{T}_{\mathrm{C}}\right)$ including a mud cap.

Event beds along the bedform stoss side from the Southwind delta compare to FA3 (upper half of sample 42 and sample 43) and FA4 (lower half of sample 42) described from the well-bedded suites of the PortneufForestville case study. In addition to striking similarities in sedimentary structures $\left(\mathrm{T}_{\mathrm{B}}\right.$ and $\mathrm{T}_{\mathrm{C}}$ subdivisions, heavy mineral concentrations, mud drapes, bioturbation), stoss-side deposits show progressively better developed intervals of rippled sand and an overall grain-size fining along slope. Maximum median grain-size distinctively decreases from the trough (sample 41, FA1type deposits ) to the stoss (sample 42), while grain-size patterns then only gradually 


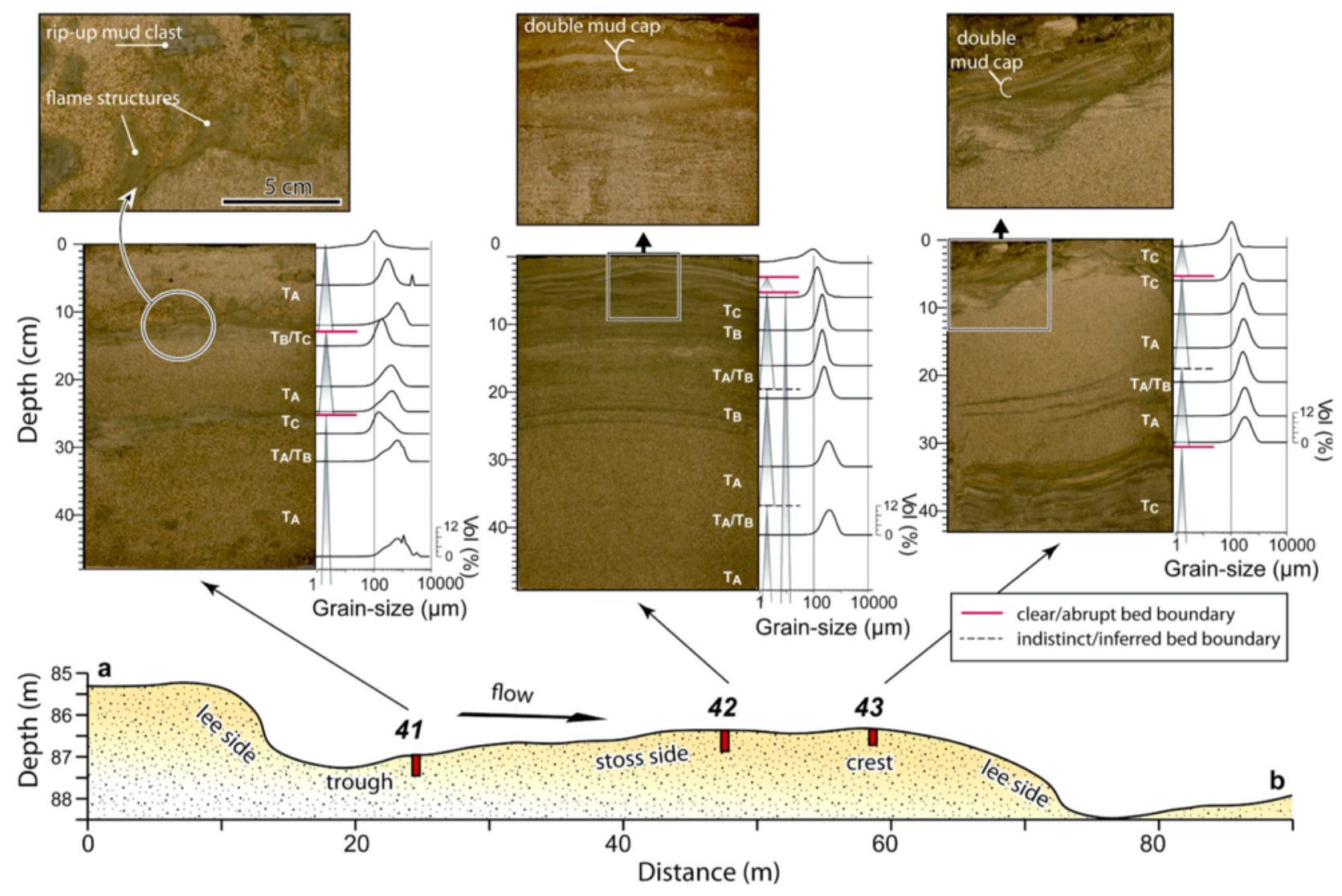

Fig. 14. Cross-sections - and close-up views - collected near the trough, on the middle stoss and on the crest of a single cyclic-step bedform illustrating the variation in sedimentary facies (location map in Fig. 13A; Southwind Fjord delta slope, Baffin Island). The trough consists of poorly-sorted gravel and sand with rip-up mud clasts while the stoss and crest consist of top-cut-out turbidites with $\mathrm{T}_{\mathrm{A}}, \mathrm{T}_{\mathrm{B}}\left(\mathrm{T}_{\mathrm{B}-1}\right.$ or $\mathrm{T}_{\mathrm{B}-2)}$ ) and $\mathrm{T}_{\mathrm{C}}$ subdivisions. Vertical and lateral grain-size distributions are given. The close-up view of sample 41 is from a cross-section distinct from the one that is illustrated here. To be compared with Figs 7C, 8B, 9 to 11 from the Portneuf-Forestville case study. 
evolve from the stoss to the crest where FA3type and FA4-type deposits prevail (sample 43).

\section{Interpretation}

The repeat swath bathymetry from 2013 and 2014 clearly shows that sediments are not preserved on the lee side of the bedforms, which are zones of net erosion. It indicates an upslope migration of the crescentic bedforms, similar to those observed in other active submarine canyons and channels (Smith et al., 2005; Paull et al., 2010; Normandeau et al., 2014, 2020; Hughes Clarke, 2016; Hage et $a$ l., 2018). Their crescentic shape and upslope migration suggest that the bedforms are formed by cyclic steps (Cartigny et al., 2011; Hughes Clarke, 2016; Normandeau et al., 2019).

The sedimentary structures observed within one of the crescentic bedform reflect depositional conditions along a single stoss side, from the downslope end of the trough up to the crest. Facies rapidly change between the three grab samples, with non-uniform deposition within each of the grabs. Near the trough, the deposition of massive sand $\left(\mathrm{T}_{\mathrm{A}}\right)$, flames and mud clasts suggests the presence of a hydraulic jump during deposition (Postma et al., 2009). The rip-up mud clasts likely originated from the erosion of mud caps deposited during calm conditions over the seabed, similar to those observed in samples 42 and 43 . Sedimentary structures vary over the bedform from trough to stoss, changing from prevailing $\mathrm{T}_{\mathrm{A}}$ in the trough to $\mathrm{T}_{\mathrm{A}} / \mathrm{T}_{\mathrm{B}}$ and well-developed $\mathrm{T}_{\mathrm{C}}$ subdivisions on the stoss and crest (Fig. 14).

Surprisingly, these along-slope changes do not match observations made through piston coring on a single crescentic bedform generated in another modern system where cyclic steps develop (Squamish delta, Hage et al., 2018), which displayed massive sand instead. This discrepancy might be due to the disturbing nature of piston coring operations, which is known to alter sedimentary structures especially in loose, water-saturated sand. Another interpretation would be that the samples of Hage et al. (2018) were mainly representative of scour deposits, while the Southwind Fjord samples allow a better identification of sedimentary structures characterizing the bedform stoss side.

Along-slope changes are in part consistent with conceptual models of cyclic steps that predict deposition of massive $\mathrm{T}_{\mathrm{A}}$ subdivisions in the trough of cyclic steps where hydraulic jumps occur (Postma and Cartigny, 2014; Slootman and Cartigny, 2020). However, according to the same models, an increase in flow strength is expected along the bedform stoss side and up to the crest, owing to a re-acceleration of the flow leading to renewed supercritical flow conditions. Related depositional facies include superimposed top-cut-out turbidites (Cartigny et al., 2011; Postma and Cartigny, 2014; Postma et al., 2014). In the Southwind Fjord case study, the downslope development of rippled sand from the stoss to the crest indicates a significant contribution of depositional conditions characterized by a decreasing flow strength along the bedform stoss side. Rippled sand, some of which deposited in the trough, and some genetically associated with mud caps, questions potential relationships with a coeval cyclic-step instability and suggests instead that alternative flow conditions prevailed over the entire delta slope when ripples were formed. As discussed below, flow fluctuations and associated deposits significantly contribute to deposition within sedimentary wedges that are related, at least temporarily, to cyclic-step processes. Regardless, the grab samples in Southwind Fjord clearly show depositional structures analogous to the lithofacies documented at outcrop in the PortneufForestville fossil delta slope (compare Fig. 14 with Figs $7 \mathrm{C}$ and $8 \mathrm{~B}$ ). Comparison of the two systems allows discussion of the nature of these flow variations in depositional systems tied to cyclic steps.

\section{DISCUSSION}

\section{Fossil versus modern}

In this study, the understanding of depositional processes builds upon a set of three comparisons: (i) lithofacies and grainsize patterns from the Portneuf-Forestville delta-slope deposits match those recovered in grabs from the Southwind Fjord delta slope (compare Figs 7, 9 and 14); (ii) stratal patterns from the Portneuf-Forestville deltaic complex (Figs 5 and 6) are a reminiscence of synthetic stratigraphies obtained using repeat swath bathymetry along the Squamish delta slope (Fig. 12B; Hage et al., 2018; Vendettuoli et al., 2019; Englert et al., this issue); (iii) the Southwind and Squamish 
delta slopes are characterized by very similar upslope-migrating bedforms, also typifying several other high-latitude deltas (Fig. 1). In these three case studies (PortneufForestville, Southwind Fjord and Squamish) that have in common an overall sedimentary background fed by glaciofluvial sources (Table 1; Normandeau et al., 2019), cyclicstep instabilities have been inferred on the basis of stratal patterns (PortneufForestville, Squamish), depositional facies (Portneuf-Forestville, Southwind Fjord), repeat swath bathymetry (Southwind Fjord, Squamish) and direct monitoring (Squamish; Hughes Clarke, 2016). In all three cases, related bedforms are confined to delta-slope channels, as is generally the case in modern examples (Fig. 1). Considering the fossil case study of Portneuf-Forestville, this is inferred from the occurrence of deep scours underlining the stratigraphic contact between upper and lower delta slope deposits (Fig. 3A), which documents a location nearby a channel-lobe transition (see Pohl et al., 2019 for present-day analogous features in the Squamish delta).

Therefore, it is argued that the depositional array (facies tracts and stratal patterns) documented from the fossil case study was formed by the development of delta slope and associated bedforms equivalent to those of the present-day case studies. Conversely, the development of the current Southwind Fjord -and Squamishbedforms should ultimately emerge in a depositional record akin to that of the Portneuf-Forestville exposure (Fig. 12). Based on the analogy between the Southwind Fjord active depositional system and the Portneuf-Forestville sedimentary record, the latter integrating tens to hundreds of years of delta development, the understanding of past sedimentary dynamics can therefore leverage the wealth of data acquired over equivalent modern cyclic steps bearing systems like the Squamish delta (Hughes-Clarke, 2016; Clare et al., 2016; Covault et al., 2017; Hage et al., 2018; Hizzett et al., 2018; Vendettuoli et al., 2018; Kostic et al., 2019; Englert et al., this issue).

The flow-parallel width of individual well-bedded suites only rarely exceeds $10 \mathrm{~m}$ (Figs 5 and 6) but geometric reconstruction clearly indicates that the wavelength of the formative bedforms was much greater $(>20$ $\mathrm{m}$; Fig. 12A), yet not as long as the wavelength of the cyclic-step bedform sampled in Southwind Fjord (Fig. 13A). The sampled Southwind Fjord stoss side, 40 to 50 $\mathrm{m}$ long, is representative of a bedform slightly more distal and deeper $(c a 80 \mathrm{~m})$ that those that generated the Portneuf-Forestville stratal pattern, as suggested by: (i) the geometrical foreset reconstruction, which has allowed to position the Portneuf-Forestville upper delta-slope depositional depths in the 20 to $60 \mathrm{~m}$ range (Dietrich et al., 2017b); and (ii) the general downslope increase of bedform wavelength along modern delta slopes (Figs 1 and 2B; see also Normandeau et al., 2016). In terms of geometry, bedform wavelengths and dip of the reconstructed "averaged" fossil delta slope (a few degrees) should be similar to those of a shallower segment of the Southwind delta slope. It is noted that the synthetic stratigraphy reconstructed from the Squamish case study was obtained from a segment of a channel lying at similar water depth (Hage et al., 2018) and showing comparable geometrical parameters (Hughes Clarke, 2016). In both cases, bedform wavelengths and heights are in the 20 to 40 $\mathrm{m}$ and 2 to $3 \mathrm{~m}$ ranges, respectively, and average delta slope is 5 to $6^{\circ}$ (Figs 5 and 12).

\section{The significance of the well-bedded suites (FA3 and FA4)}

Deposition from cyclic-step instabilities, or from waning or pulsating flow conditions linked to cyclic-step instabilities, has been well established considering sedimentary structures and stratal pattern related to FA1 and FA2 deposits from the PortneufForestville delta slope. The latter are, however, restricted to pseudo-channels and isolated scour fills along the pseudo foresets (Figs 5, 6 and 8). It has also been noticed above that depositional patterns of FA3 and FA4 deposits cast some doubt about a direct genetic relationship with cyclic-step instabilities.

The accretion of FA3 and FA4 deposits and resulting well-bedded suites is essentially characterized by quasi-draping geometries, with limited or lack of lee-side erosion (Figs 5, 6, 12 and 15). Although the well-bedded suites are comparable to the lamination pattern expected from sustained fully to partially depositional cyclic steps in the sense of Slootman and Cartigny (2020), bioturbated horizons and/or 0.5 to $10 \mathrm{~cm}$ thick extensive mud drapes evidence numerous flow interruptions within the well-bedded suites. Similar indications come from the Southwind Fjord record. Flow interruptions 
indicate that well-bedded suites - and their constitutive event beds- were deposited by successive and distinct flow events separated by periods of relative quiescence. In no circumstances was a single well-bedded suite (FA3, FA4) formed by one sustained supercritical flow event responsible for the $\mathrm{m}$ scale aggradation of a partially to fully depositional cyclic-step bedform. As shown by monitoring and synthetic stratigraphies reconstructed from repeat swath bathymetry, stratal patterns similar to well-bedded suites over the Squamish delta slope (Fig. 12B) also formed after a superimposition of distinct short-lived flow events, generally less than 10 minutes in duration (Hizzett et al., 2018; Hage et al., 2019), of which only a few correspond to supercritical flow conditions (Hughes Clarke, 2016).

The hypothesis that well-bedded suites might result solely from a succession of distinct cyclic-step instabilities would imply a lack of any other intervening flow types (with the exception of those tied to post-cyclic-step waning-flow conditions). The quasi-draping bed conformation and/or restricted lee-side reworking would have been, in this hypothesis, the result of cyclic-step instabilities with flow properties precisely and recurrently adjusted to the pre-existing cyclic-step morphology. Since such a consistency is unlikely, it is reasonable to assume that the bedforms, apparently linked to the well-bedded suites, do not chart the proper hydrodynamic signature of a parent flow but rather the response of an interaction between a train of pre-existing bedforms and a superimposed flow (see also Normandeau et $a l ., 2020)$. It is contended that the currents originating the bulk of the well-bedded suites of the Portneuf-Forestville delta-slope deposits do not correspond to flow dynamics envisioned from numerical or conceptual models for cyclic steps (e.g. Vellinga et al., 2018; Slootman and Cartigny, 2020). Rather, well-bedded suites and related FA3 and FA4 deposits are interpreted as the result of turbidity currents decelerating along the stoss of former cyclic-step bedforms and reaccelerating over their lee sides (Fig. 15C). In this scheme, the density flows accrete principally over the stoss sides (e.g. Fig. 11), in some cases over the lee sides (Fig. 6), and only marginally rework the bedform lee sides. Minor erosion capacity and/or short duration of the successive turbidity currents result in transposition of an anterior cyclically-stepped topography that is principally preserved during delta-slope aggradation.

This interpretation, invoking flow conditions that are relatively uniform at the bedform scale and distinct from those of depositional cyclic steps is corroborated by: (i) the total absence of any hydraulic jump deposits in the quasi-draping beds of the wellbedded suites on the Portneuf-Forestville delta slope; (ii) sand beds juxtaposed on either side of a pseudo-foreset that show similar structures and thicknesses (Fig. $7 \mathrm{~A}$ and B); (iii) the downcurrent decreasing grain size over one bedform wavelength, relatively subtle along the stoss side up to the crest (Fig. 11; see also Fig. 14), which mostly typifies the upper lee side where flow strength is however supposed to significantly increase (Vellinga et $a l ., 2018$ ); (iv) restricted erosion of the lee side that appears to have mainly occurred in the form of local winnowing processes, as evidenced by occurrences of heavy mineral layers and the general lack of deep scours (Figs 6 and 7B) and; (v) no influx of material coarser than that already present in the adjacent well-bedded suite.

Similar observations have been made along the bedform sampled in Southwind Fjord. In the trough, two event beds show FA1-type deposits, but the intervening bed does not bear any evidence for a nearby hydraulic jump. The intervening bed is similar to those beds observed downslope along the stoss and up to the crest (Fig. 14). Here, the increasing development of rippled sand rather suggests flow deceleration and increasing sedimentation rates over an upslope dipping depositional surface rather than the expected general flow acceleration over the stoss side of a cyclic step. The fact that flows traveling over cyclically-stepped surfaces are not necessarily cyclic steps was also suggested on the basis of flow monitoring in some other case studies (Hughes-Clarkes, 2016; Normandeau et al., 2020).

\section{Toward a dual flow model?}

Flows generating the well-bedded suites may have been either subcritical or supercritical, yet at a Froude number less than that associated with cyclic steps. Steep gradients $\left(c a 6^{\circ}\right)$ over the delta slopes definitely favour supercritical flows. If cyclic steps resulting in FA1 and FA2 are interpreted as linked to the supercritical dense basal layer of stratified turbidity currents (Fig. 15A), the bulk of the well-bedded suites ( $\mathrm{T}_{\mathrm{A}}$ and $\mathrm{T}_{\mathrm{B}}$ subdivisions of 

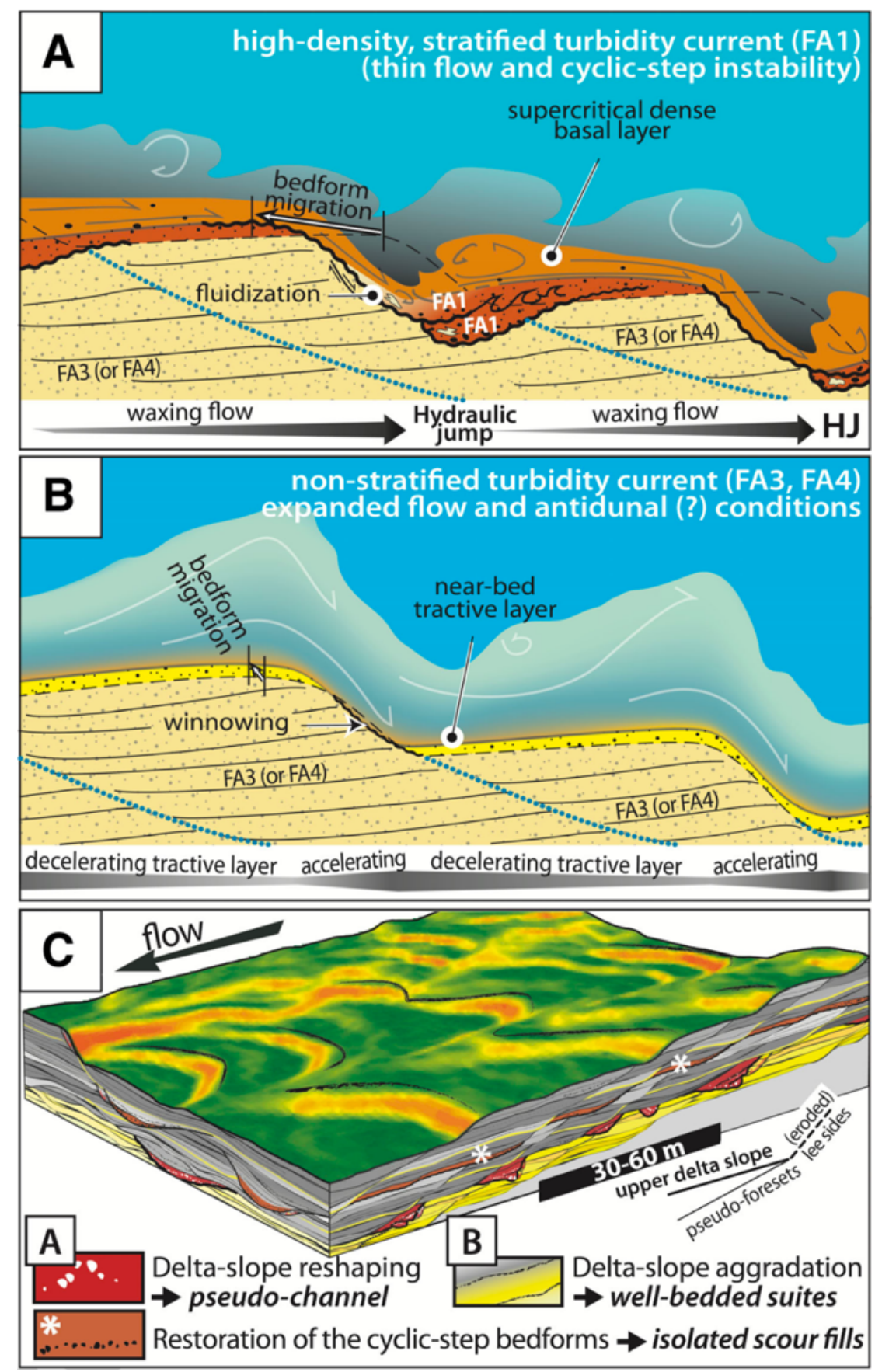

Fig. 15. The depositional signature of cyclic-step instabilities. (A) Cyclic steps, which lead to episodes of significant delta-slope reshaping, truncate earlier deposits (FA3 and FA4) and intervening pseudo-foresets (cf. Fig. 15B). They are interpreted to develop in association with the supercritical basal layer of dense (stratified) turbidity currents, here represented in orange. The depositional record of cyclic steps, constituting chiefly the infill of pseudo-channels, is interpreted as the result of "cyclic-step flow events". Such events encompass a tract of flow conditions from the fully erosional cyclic steps that might have developed in an initial flow stage (not shown) up to late waning-flow conditions. They must include flow conditions corresponding to partially depositional cyclic steps sensu Slootman and Cartigny (2020) and to other transient flow stages such as antidunes (FA1 and FA2, respectively). (B) Successions of short-lived, expanded (non-stratified) turbidity currents, possibly under antidunal conditions, are suggested to explain the aggradation of top-cutout turbidites forming well-bedded suites (FA3 or FA4) and associated pseudo-foresets (blue dotted lines). In this case, depositional patterns are related to the interaction of a near-bed tractive layer underlining a thick flow (in orange) with morphologies inherited from pre-existing cyclic-step bedforms (cf. Fig. 15A). Though showing a stratal pattern analogous to that of depositional cyclic steps, FA3 and FA4 deposits do not result directly from cyclic-step instabilities. (C) Stratal pattern resulting from the occurrence of episodic cyclic-step instabilities and intervening flow conditions in a proglacial delta-slope setting. Flow-parallel (right) and flow-perpendicular (left) cross-sections are dominated by pseudo-foreset and pseudo-channel geometries, respectively. The bulk of sand (grey and yellow, FA3 and FA4; Fig. 15B) was deposited over cyclically-stepped morphologies, reworking and translating upslope bedforms inherited from former cyclic-step flow events that periodically reshaped the delta slope (red, FA1, FA2, Fig. 15A). Cyclic steps during subordinate flow events are also invoked in explaining the formation of some isolated scours and associated lenticular beds along the pseudo-foresets (white stars, see also Fig. 16). Note that, for the sake of clarity, waning-flow conditions are not accounted for in panels A to C. The resulting deposits, such as short wavelength antidunes (FA2), climbing-ripple cross-lamination and/or mud drapes however contribute to facies associations (Table 2; Fig. 16). 
FA3 and FA4 deposits) most likely relate to another type of supercritical flow, which might be associated with a thicker, less dense, essentially non-stratified turbidity current (Fig. 15B). Deposition would have been governed in this case by the interaction of a near-bed tractive layer with inherited cyclically-stepped morphologies. Antidunal flow conditions might be inferred considering: (i) flow deceleration along the stoss sides and flow acceleration along the lee sides (Fig. 15B); and (ii) the lack of any evidence for hydraulic-jump processes (see also Cartigny et al., 2011; West et al., 2019). Associated upslope bedform migration would not necessarily chart the intrinsic properties of the parent flow, but an indirect consequence of this interaction. It is noted that resulting morphologies might not correspond to typical long-wavelength antidune bedforms owing to the short duration of individual flow events. Each expanded flow is most probably unable on its own to effectively reorganize the delta slope. The resulting seabed thus remains largely a reflection of the inherited, more or less transposed cyclic-step morphologies. Moreover, depositional and winnowing processes that may occur during waning-flow conditions and between two successive expanded turbidity currents can also alter the geometry of any antidune bedform.

A dual flow model has been previously discussed in the case of deep-sea sediment waves (Lee et al., 2002; Normark et al. 2002). Although the antidune interpretation needs to be further corroborated by future direct flow monitoring along delta slopes, it is noted that the dual flow model matches some observations in cyclically-stepped depositional systems where two types of flows have been monitored. The first type is strongly erosive and definitely involves a supercritical dense basal layer, interpreted as the result of effective flow stratification (e.g. Migeon et al., 2012; Talling et al., 2015; Paull et al., 2018). The second one is less erosion-prone and typically lacks a dense basal layer (Hughes Clarke, 2016; Hage et al., 2019; Normandeau et al., 2020). In the dual flow model, both types correspond to supercritical flows over the delta slope, though characterized by distinct flow conditions involving a dense basal layer and an overall expanded flow, respectively (Fig. 15).

\section{A facies model for delta slopes impacted by cyclic steps}

A significant part of the delta-slope deposits from the Portneuf-Forestville and Southwind Fjord case studies is interpreted to result from supercritical turbidity currents associated with expanded flows, which are less dense than the flows able to develop cyclic steps (Fig. 16). The stepped geometry of the delta slope, which is inherited from - and periodically reshaped by - antecedent and intervening cyclic-step instabilities, is however maintained during such flows. Only erosional cyclic steps are able to reshape the delta slope, the height and wavelength of the resulting bedforms being directly linked to properties of the supercritical dense basal layer of the parent flow. Based on the Portneuf-Forestville case study, the relative proportion of deposits positively linked to cyclic steps is estimated to less than $20 \%$ of the upper delta-slope succession (Fig. 15A).

A delta slope occasionally impacted by cyclic-step instabilities is suggested to include the following three distinct stages of delta-slope development (Figs 15 and 16): (i) delta-slope reshaping by cyclic steps during major supercritical flow events (pseudochannels and related infills); (ii) delta-slope aggradation linked to expanded turbidity currents, possibly developing antidunal conditions, and flowing over inherited cyclically-stepped morphologies (well-bedded suites and intervening pseudo foresets); (iii) restoration of cyclic-step bedforms by episodic and subordinate supercritical flow events (marked isolated scour fills along the pseudoforesets).

Delta-slope reshaping by cyclic steps

Along the upper delta slope, the main signature of high-density Froudesupercritical flows is erosion surfaces, which are highlighted by pseudo-channel incisions. Active erosion of the bedform lee sides occurs at this stage and such flows result in a significant reshaping of the delta slope and associated bedforms. If subsequent deposition in the bedform troughs indicates the contribution of partially depositional cyclic steps (sensu Slootman and Cartigny, 2020), fully to partially erosional cyclic steps most likely contributed to initial erosion (Dietrich et al., 2016). Also, a significant part of the deposits linked to cyclic steps (FA1, FA2) represents fluctuating or later, out-ofequilibrium, transient conditions (Table 2; Fig. 16). Therefore, rather than referring to the development of partially depositional cyclic steps, it is here preferable to consider 
episodic "cyclic-step flow events" that involved at one point in time depositional cyclic steps. A cyclic-step flow event encompasses the whole succession of genetically linked flows and flow transitions from fully(?) or partially erosional cyclic steps up to late waning-flow conditions, including partially depositional cyclic steps sensu Slootman and Cartigny (2020). The latter flow conditions might have been in fact rather short-lived within such a cyclic-step flow event.

In the Southwind Fjord, such events able to significantly reshape the delta slope most probably did not happen in the 20132014 time range (Fig. 13) but occurred at least once from 2014 to 2018 (Fig. 2B). It is however suspected that corresponding deposits have not been sampled in the first few decimeters below sea floor. Indeed, the latter represent the more recently deposited sand, where only thin deposits demonstrably linked to a hydraulic jump have been identified.

Beneath the dense basal layer of associated turbidity currents, lee-side excavation yields steepened erosion surfaces affected by ubiquitous gravitational deformation (Postma et al., 2014; Lang et al., 2017) and liquefaction processes (see also Paull et al., 2018). Active sediment erosion and partial mixing into the dense basal layer may have caused flow acceleration along the upper delta slope, the dense basal layer likely being the driver of the overall density flow (self-accelerating turbidity currents sensu Parker et al., 1986). Cyclic-step deposits in the trough and over the proximal stoss side correspond to a superimposition of $<1 \mathrm{~m}$ thick facies sequences (Fig. 10) characterized by: (i) active liquefaction highlighted by sheared flame structures (Figs 6 and 14); (ii) the deposition of thick massive beds (FA1) incorporating river-derived gravel-sized clasts and including 1 to $20 \mathrm{~cm}$ rip-up clasts from the nearby truncated succession (Figs 8B, 9 and 14); and (iii) by recurrent intercalations of faintly to well laminated sand at the base of the lee side (FA2, Fig. 8C). Most of these features are reproduced in flume-tank experiments (e.g. Ono et al., in press) and can be linked to the development and migration of active hydraulic jumps and related pressure variations at the bed. Note that FA2 deposits, interpreted as superimposed antidune deposits at the base of the lee sides, are thought to be linked to intervening flow pulsations or post-cyclic-step waning-flow conditions (see also Dietrich et al., 2016). As they are linked to shortwavelength antidunes originated from the supercritical dense basal layer, these deposits are thus fundamentally different from expanded antidunal flow conditions that have been inferred for the well-bedded suites. The occurrence of ripple laminated sand is understood as deposition from overlying dilute turbidity current either permitted by a temporary tearing of the high-density layer (flow pulsations?) or recording a waning-flow stage between two successive cyclic-step instabilities (Hughes Clarke, 2016).

\section{Delta-slope aggradation linked to expanded turbidity currents}

The signature of time periods dominated by expanded turbidity currents is the progressive aggradation of turbiditic bedsets over inherited cyclically-stepped morphologies, ultimately forming the well-bedded suites. Restricted lee-side erosion and generalized stoss-side deposition occurred at this stage. The superimposition of successive supercritical expanded density flow deposits resulted in upslope migrating bedforms and pseudoforesets (Figs 12A and 15C), which mimics but does not correspond to - the stratal patterns predicted for sustained, highaggradation, fully to partially depositional cyclic steps (Cartigny et al., 2011; Slootman and Cartigny, 2020). In the Southwind Fjord, the 2013-2014 time range likely corresponds to such a delta slope aggradation, without any intervening significant event of delta-slope reshaping (Fig. 13).

Delta-slope aggradation results from deposition of thin-bedded (5 to $20 \mathrm{~cm}$ thick) top-cut-out turbidites and turbiditic bedsets repeatedly bounded by pseudo-foresets (Figs 6, 8, 12 and 15B). Deciphering the $\mathrm{T}_{\mathrm{A}}$ and $\mathrm{T}_{\mathrm{B}}$ subdivisions in individual beds may be challenging, suggesting however incremental deposition from sustained high-density currents rather than en-masse deposition (Kneller and Branney, 1995; Talling et al., 2012; Hughes Clarke, 2016). Assuming an individual flow duration on the order of minutes in proglacial deltas (Hughes Clarke, 2016), the fining-up and thinning-up trends noted at the $\mathrm{m}$-scale within bedsets of the well-bedded suites (Fig. 7C) suggest a tidal modulation of the flow strength of separate, successive turbidity currents occurring daily or several days apart. This is in line with recent findings suggesting that turbidity currents in the Squamish are likely triggered 


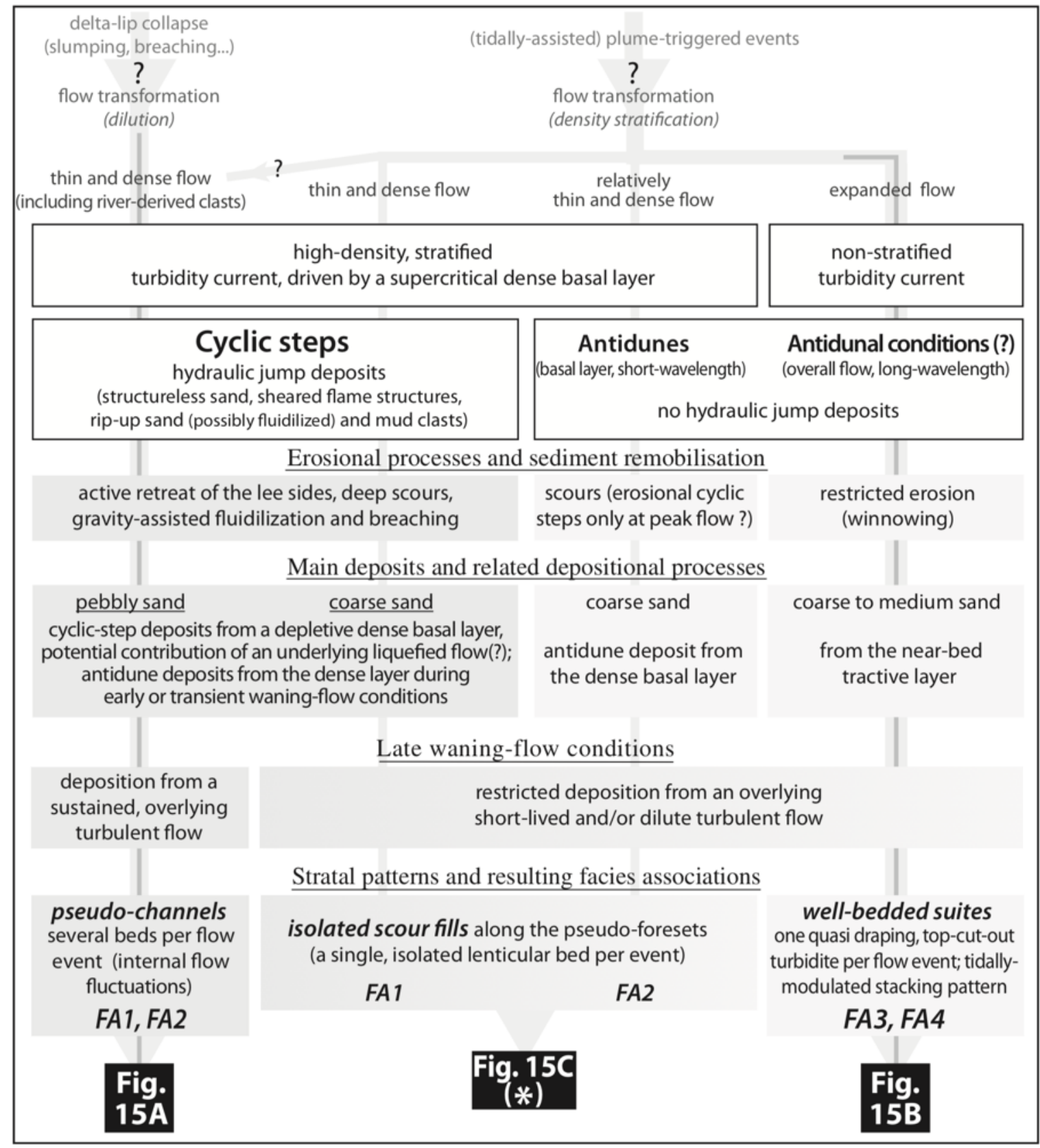


at low tide from ebb-tide river wash load (Hughes Clarke, 2016; Hizzett et al., 2018; Hage et al., 2019).

Heavy mineral layers are ubiquitous and are observed forming within-bed lamination (highlighting horizontal lamination of the $\mathrm{T}_{\mathrm{B}-2}$ subdivision), along inter-bed contacts and/or marking grain-size breaks characterizing the transition from high- to lower-density flows (Fig. 7C; Talling et al., 2012). Rippled bed tops are frequent, yet better developed in the lower, i.e., deeper part of the delta-slope succession (prevailing FA3; Fig. 6). Waning-flow conditions are typically marked by trains of starved ripples separating two successive event beds (Fig. 9). It suggests that waning-flow conditions associated with well-bedded suites corresponded to more dilute and/or shorter-duration turbidity currents relative to those succeeding to cyclic-step flow events - the latter resulting in the thicker assemblages of climbing-ripple cross-lamination observed in FA1. Bed amalgamation prevails in the shallower segment of the upper delta slope (FA4, e.g., Fig. 9 with photograph location in Fig. 5), where a depositional context within a channel cannot be admittedly guaranteed.

\section{Restoration of the cyclic-step bedforms}

The occurrence of subordinate episodic erosion events may temporarily interrupt delta-slope aggradation stages. Such a stage is suggested in the Portneuf-Forestville case study by isolated scour fills showing FA1 and/or FA2 deposits sparsely distributed along the pseudo-foresets (white stars in Fig. 15C; and Fig. 16). Although interpreted as the signature of a cyclic step instability (Fig. 16), related scours are not able to significantly reshape the delta slope. As a consequence, no fundamental change in the stratal pattern occurs and renewed sediment aggradation resumes afterwards. Such density flows are nevertheless able to steepen again the lee sides, reactivating and maintaining a train of genuine cyclic-step bedforms over the delta slope. Cyclic-step deposits near the trough (grab 41, Fig. 14) of the sampled bedform along the Southwind delta slope are understood to be the result of such a type of subordinate cyclic-step instability.

The flow event monitored and formally interpreted as a cyclic-step instability by Hughes Clarke (2016) on the Squamish delta shares a number of characteristics with such type of cyclic steps (a flow thickness of a few metres, a resulting lenticular sand body, 1 to $2 \mathrm{~m}$ of lee-side erosion). This event was able to restore cyclicstep bedforms, which however only partially modified the pre-existing seabed that was itself largely inherited from a previous major cyclic-step instability (Hughes Clarke, 2016).

\section{Timing and origin of turbidity currents}

Whatever the exact contribution of cyclic steps and related turbidity-flow dynamics, it has been noticed above that stratal patterns preserved in the Portneuf-Forestville succession, and stratal patterns from the Squamish upper delta slope (Hage et al., 2018) are, at least geometrically speaking, very similar (Fig. 12). Well-bedded suites overlying pseudo-channels of the fossil succession are analogous to the backstepping beds deposited above series of amalgamated scour fills as reconstructed from the modern case studies (see also Lang et al., 2017; Ono and Plink-Björklund, 2018). In both cases, an aggradational regime succeeds a period dominated by a succession of cyclic-step flow events including erosion components (erosional cyclic steps and/or scours linked to low-aggradation, partially depositional cyclic steps; Slootman and Cartigny, 2020). The result is an erosion-based facies sequence (Fig. 15A), several of which can be delineated across the Portneuf-Forestville exposure (Figs 3, 5 and 6). It is here proposed that such a facies sequence, wherever it is preserved (see Vendettuoli et al. 2019; for incompleteness issues), represents the building block corresponding to a delta-slope clinothem temporarily impacted by (this facies model), or essentially resulting from (e.g. Hage et al. 2018; regarding the Squamish case study) cyclic-steps developed over the upper delta slope. A stratigraphic superimposition of successive, several mthick, erosion-based facies sequences will define at the $100 \mathrm{~m}$ scale a cyclic arrangement within the delta-slope deposits.

Considering the Squamish case study, Hizzett et al. (2018) have suggested that plume-triggered events - settling from surface (hypopycnal) river plumes - dominate the generation of depositional turbidity currents over the proglacial delta slope. Highly erosive turbidity currents are less frequent and originate either from plumetriggered events typically linked to high river discharges or from small-scale submarine landslides rapidly mixing with ambient water and combined with channel-wall failures (Fig. 2B). Other significant depositional events are 
linked to larger submarine landslides, in which case restricted mixing does not allow the formation of a turbidity current along the upper delta slope. As a working hypothesis, and by analogy with the Squamish delta dynamics (Hizzett et al., 2018; Hage et al., 2019), well-bedded suites are interpreted as resulting from depositional plume-triggered events that remain expanded and relatively dilute. On the other hand, it can be considered that delta-slope reshaping events by cyclic steps, as well as episodes of restoration of the cyclic-step bedforms, are related to erosive turbidity currents; their dense basal layer developing, at least temporarily, a cyclic-step instability (Fig. 16). Turbidity flows resulting in delta-slope reshaping however specifically carry and deposit pebbly sand (FA1 deposits), i.e., a sediment directly derived from the shallowest segments of the slope. It suggests a specific relationship with delta lip failures. Flow fluctuations within the superimposed cyclicstep deposits is in agreement with such an interpretation, considering common polyphase slumping or breaching events (e.g. Mastbergen and Van Den Berg, 2003). In this scheme, the aforementioned erosion-based facies sequence likely represents an annual or seasonal signal, freshet episodes or neapspring tidal cycles being at play. Turbidity flow events developing cyclic steps able to reshape the delta slope would preferentially occur during the first part of the freshet (June, July). They are potentially enhanced by a variety of tidal processes during spring tides (tidal drawdown: Clare et al., 2016; Dietrich et al., 2016; tidal turbidity maximum: Hage et al., 2019). Any other conjunction of a peak in river discharge with an especially low tide may, however, also generate an erosive turbidity current (Hage $e t$ al., 2019). Erosive plume-triggered turbidity currents are tentatively associated to episodes of restoration of the cyclic-step bedforms along the delta slope (isolated scour fill along the pseudo-foresets, Fig. 16). Such events might be relatively frequent and more easily monitored along modern delta slopes.

If the model is valid, stratal patterns and their associated depositional facies in the Portneuf-Forestville delta-slope succession are representative of the variety of flow properties recognized along modern delta slopes (Hughes Clarke, 2016; Hizzett et al., 2018; Hage et al., 2019). Thus, in this deltaic setting, any depositional record would include (Fig. 16): (i) cyclic steps linked to delta-lip failures, representing occasional, yet instrumental events linked to a supercritical dense basal layer remobilizing both delta-lip and delta-slope sediment; (ii) cyclic steps linked to erosive plume-triggered events, representing more frequent but less efficient episodes, though also linked to the development of a supercritical dense basal layer; and (iii) supercritical expanded flows linked to frequent and essentially depositional plume-triggered events that drive delta-slope aggradation, either until a particular delta-slope channel is gradually filled in, and/or preferentially in interchannel areas. Froude-supercritical dense basal layers shape erosional cyclic-step bedforms and transfer a significant part of their total sediment load down to the lobe. In contrast, supercritical but expanded currents traveling and decelerating over inherited trains of cyclically-stepped morphologies essentially contribute to the delta slope accretion, before they reach the lobe. However, as noted by Hizzett et al. (2018), the relative contribution of plume-triggered turbidity currents to lobe aggradation remains significant because the latter events are more frequent than instrumental but episodic cyclic steps. Such relationship is also reflected in the delta-slope succession of the Portneuf-Forestville deltaic complex by the relatively low contribution of deposits related to cyclic steps (FA1, FA2) compared to deposits from plume-triggered expanded flows (FA3, FA4) (Figs 15A and 16).

\section{CONCLUSIONS}

Cyclic steps have been the subject of numerous studies in recent years. Their recognition in the depositional record as the result of upslope-migrating bedforms has, however, remained so far challenging. Extensive exposures of a fossil deltaic succession (Portneuf-Forestville deltaic complex, Québec North Shore) are combined for the first time with datasets from analogous, modern, sand-dominated, delta slopes typified by crescentic bedforms, including cores from the Southwind Fjord (Baffin Island). The depositional architecture of the fossil case study is thus understood in the light of the modern bedform characteristics (e.g., upslope migration, bedform asymmetry and wavelength, sedimentary structures). Based on natural laboratories, the work allows the stratal 
pattern arising from the development of cyclic-step bedforms to be deciphered, complementing flume-tank and numerical model inferences.

High-density (stratified) flows traveling, eroding and depositing over upslopemigrating bedform systems were involved, but significant depositional stages were not linked temporally to cyclic steps and associated hydraulic jumps. Instead, two basic modes tied to upslope-migrating bedforms are delineated here: (i) cyclic-step flow events, linked to Froude-supercritical flow conditions in the dense basal layer of a high-density (stratified) turbidity current. The results are essentially the sculpting of cyclic-step bedforms, the deposition of hydraulic-jump-related gravelly sand, and the transfer of most of the sediment charge toward deeper segments of the delta slope (lobes); (ii) depositional turbidites, also interpreted as resulting from Froudesupercritical (possibly antidunal) flow conditions, yet involving expanded (nonstratified) turbidity currents. The near-bed tractive layer of the latter interacted at the bedform scale with the cyclically-stepped delta slope inherited from a former cyclic-step instability. Flow modification involves local re-acceleration and minor sediment reworking over steep lee sides and deposition along, and thus aggradation of the stoss sides; morphologies being "copy-pasted" by quasidraping from the bedforms resulting from a previous cyclic-step flow event. Aggradation by successive expanded turbidity currents prevails up to the occurrence of renewed cyclic steps that are able to restore a train of genuine bedforms. Although less frequent than other flow conditions, flows associated with cyclic steps and related bedforms impose their geometry, impacting the succeeding, longer-term stage of delta-slope development.

\section{ACKNOWLEDGEMENTS}

We acknowledge the thorough comments by the Associate Editor A. Slootman and constructive and helpful reviews of S. Hage and two anonymous reviewers, which helped us to improve the paper. The field campaign was funded by the TELLUS-Marge project of the CNRS-INSU, attributed to JFG. We thank the scientific cruise participants of CCGS Hudson 2018042 for their help during the grab sample acquisition, particularly Kate Jarrett, Makeala MacIntyre, Angus Robertson, Peter Pledge, Tom Carson, Des
Manning, Kevin MacKillop and Meaghan Macquarrie. Makaela MacIntyre drafted Fig. 4. AN acknowledges the Program for Energy Research and Development of Natural Resources Canada and Crown-Indigenous Relations and Northern Affairs Canada (CIRNAC) for financial support. We thank ArcticNet for the 2013 and 2014 swath bathymetry data of Southwind Fjord. Part of this work was also supported by an NSERC Discovery Grant to PL. We declare no conflict of interest. 


\section{REFERENCES}

The data that support the findings of this study are available from the second author (alexandre.normandeau@canada.ca) upon reasonable request.

Amos, C.L., Li, M.Z., Chiocci, F.L., La Monica, G.B., Cappucci, S., King, E.L. and Corbani, F. (2003) Origin of shore-normal channels from the shoreface of Sable Island, Canada. J. Geophys. Res., 108, 3094. DOI: 10.1029/2001JC001259 [online]

Ashley, G. M., Southard, J.B. and Boothryod, J.C. (1982) Deposition of climbing ripple beds: a flume simulation. Sedimentology, 29, 67-79.

Ayranci, K., Lintern, D.G., Hill, P.R. and Dashtgard, S.E (2012) Tide-supported gravity flows on the upper delta front, Fraser River delta, Canada: Mar. Geol., 326-328, 166-170.

Cartigny, M.J.B., Postma, G., van den Berg, J.H. and Mastbergen, D.R. (2011) A comparative study of sediment waves and cyclic steps based on geometries, internal structures and numerical modeling. Mar. Geol., 280, 40-56.

Cartigny, M.J.B., Ventra, D., Postma, G. and van Den Berg, J.H. (2014) Morphodynamics and sedimentary structures of bedforms under supercritical-flow conditions: New insights from flume experiments. Sedimentology, 61, $712-748$.

Clare, M.A., Hughes Clarke, J.E., Talling, P.J., Cartigny, M.J.B. and Pratomo, D.G. (2016) Preconditioning and triggering of offshore slope failures and turbidity currents revealed by most detailed monitoring yet at a fjord-head delta. Earth Planet. Sc. Let., 450, 208-220.

Cornard, P.H. and Pickering, K.T. (2019) Supercritical-flow deposits and their distribution in a submarine channel system, Middle Eocene, Ainsa Basin, Spanish Pyrenees. J. Sediment. Res., 89, 576-597.

Covault, J.A., Kostic, S., Paull, C.K., Ryan, H.F. and Fildani, A. (2014) Submarine channel initiation, filling and maintenance from sea-floor geomorphology and morphodynamic modelling of cyclic steps. Sedimentology, 61, 1031-1054.

Covault, J.A., Kostic, S., Paull, C.K., Sylvester, Z. and Fildani, A. (2017) Cyclic steps and related supercritical bedforms: Building blocks of deep-water depositional systems, western North America. Mar. Geol., 39, 4-20.

Dietrich, P., Ghienne. J.-F., Normandeau, A. and Lajeunesse, P. (2016) Upslope-migrating bedforms in a proglacial sandur delta: Cyclic steps from river-derived underflows? $J$. Sediment. Res., 86, 113-123.
Dietrich, P., Ghienne. J.-F., Normandeau, A. and Lajeunesse, P. (2017a) Reconstructing ice-margin retreat using delta morphostratigraphy. Scientific Rep. 7, 16936. DOI: 10.1038/s41598-017-16763-x [online]

Dietrich, P., Ghienne, J.-F., Schuster, M., Lajeunesse, P., Nutz, A., Deschamps, R., Roquin, C., and Duringer, P. (2017b) From outwash to coastal systems in the PortneufForestville deltaic complex (Québec North Shore): Anatomy of a forced regressive deglacial sequence. Sedimentology 64, 10441078.

Dietrich, P., Normandeau, A., Lajeunesse, P., Ghienne, J.-F., Schuster, M. and Nutz A. (2020) Deltaic complexes the Québec North Shore. In : Landscapes and Landforms of Eastern Canada (Eds O. Slaymaker and N. Catto), pp. 245-258, World Geomorphological Landscapes, Springer, Cham.

Duchesne, M.J., Pinet, N, Bédard, K., St-Onge, G., Lajeunesse, P., Campbell, D.C. and Bolduc, A. (2010) Role of the bedrock topography in the Quaternary filling of a giant estuarine basin: The Lower St. Lawrence Estuary, Eastern Canada. Bas. Res., 22, 933951.

Englert, R.G., Hubbard, S.M., Cartigny, M.J.B., Clare M.A., Coutts D.S., Hage, S., Hughes Clarke, J., Jobe, Z., Lintern D.G., Stacey, C. and Vendettuoli, D. (this issue). Quantifying the three-dimensional stratigraphic expression of cyclic steps by integrating seafloor and deep-water outcrop observations. Sedimentology.

Fildani, A., Normark, W.R., Kostic, S. and Parker, G. (2006) Channel formation by flow stripping: large-scale scour features along the Monterey East Channel and their relation to sediment waves. Sedimentology, 53, 12651287.

Fricke, A.T., Sheets, B.A., Nittrouer, C.A., Allison, M.A. and Ogston, A.S. (2015) An Examination of Froude-Supercritical Flows and Cyclic Steps On A Subaqueous Lacustrine Delta, Lake Chelan, Washington, U.S.A. J. Sediment. Res., 85, 754-767.

Gardner, A.S., Moholdt, G., Wouters. B., Wolken, G.J., Burgess, D.O., Sharp, M.J., Cogley, J.G., Braun, C. and Labine, C. (2011) Sharply increased mass loss from glaciers and ice caps in the Canadian Arctic Archipelago. Nature, 473, 357-360.

Ghienne, J.-F., Girard, F., Moreau, J. and Rubino, J.-L. (2010) Late Ordovician climbing-dune cross-stratification: a signature of outburst bloods in proglacial outwash environments? Sedimentology, 57, 1175-1198. 
Girard, F., Ghienne. J.-F., Du-Bernard, X. and Rubino, J.-L. (2015) Sedimentary imprints of former ice-sheet margins: Insights from an end-Ordovician archive (SW Libya). Earth-Sci. Rev., 148, 259-289.

Gobo, K., Ghinassi, M. and Nemec, W. (2014) Reciprocal changes in forest to bottoms facies in a Gilbert-type delta: response to short-term changes in base-level. J. Sediment. Res., 84, 1079-1095.

Hage, S., Cartigny, M.J.B., Clare, M.A. et al. (2018) How to recognize crescentic bedforms formed by supercritical turbidity currents in the geologic record: Insights from active submarine channels. Geology, 46, 563-566.

Hage, S., Cartigny, M.J.B. and Sumner, E.J. et al. (2019) Direct monitoring reveals initiation of turbidity currents from extremely dilute river plumes. Geophys. Res. Let., 46, 1131011320.

Hizzett, J.L., Hughes Clarke, J.E., Sumner, E.J., Cartigny, M.J.B., Talling, P.J., and Clare, M.A. (2018) Which triggers produce the most erosive, frequent and longest runout turbidity currents on deltas? Geophys. Res. Letters, 45, 855-863.

Hughes Clarke, J.E., Muggah, J., Renoud, W., Bell, T., Forbes, D.L., Cowan, B. and Kennedy, J. (2015) Reconnaissance seabed mapping around Hall and Cumberland peninsulas, Nunavut : opening up southeastern Baffin Island to nearshore geological investigations. Summary of Activities 2014, pp. 133-144.

Hughes Clarke, J.E., Vidiera Marques, C.R. and Pratomo, D. (2014) Imaging Active MassWasting and Sediment Flows on a Fjord Delta, Squamish, British Columbia. In : Submarine Mass Movements and Their Consequences (Eds S. Krastel, J.-H. Behrmann, D. Völker, M. Stipp, C. Berndt, R. Urgeles, J. Chaytor, K. Huhn, M. Strasse and C.B. Harbitz). pp. 249260, Advances in Natural and Technological Hazards Research, Springer.

Hughes Clarke, J.E. (2016) First wide-angle view of channelized turbidity currents links migrating cyclic steps to flow characteristics. Nat. Comm., 7 : 11896. DOI: 10.1038/ncomms11896 [online]

Hunter, R.E. (1977) Terminology of crossstratified sedimentary layers and climbingripple structures. J. Sediment. Res., 47, 697706.

Kneller, B.C. and Branney, M.J. (1995) Sustained high-density turbidity currents and the deposition of thick massive sands. Sedimentology, 42, 607-616.
Kostic, S. (2011) Modeling of submarine cyclic steps: Controls on their formation, migration, and architecture. Geosphere, 7, 294-304.

Kostic, S., Casalbore, D., Chiocci, F., Lang, J. and Winsemann, J. (2019) Role of upperflowregime bedforms emplaced by sediment gravity flows in the evolution of deltas. J. Mar. Sci. Eng., 7, 5. DOI: 10.3390/jmse7010005 [online]

Kostic. S., Sequeiros. O., Spinewine. B. and Parker, G. (2010) Cyclic steps: A phenomenon of supercritical shallow flow from the high mountains to the bottom of the ocean. J. Hydroenv. Res., 3, 167-172.

Lang, J., Sievers, J., Loewer, M., Igel, J. and Winsemann, J. (2017) 3D architecture of cyclic-step and antidune deposits in glacigenic subaqueous fan and delta settings: Integrating outcrop and ground-penetrating radar data. Sediment Geol., 362, 83-100.

Lang, J. and Winsemann, J. (2013) Lateral and vertical facies relationships of bedforms deposited by aggrading supercritical flows: From cyclic steps to humpback dunes. Sediment. Geol., 296, 36-54.

Lee, H.J., Syvitski, J.P.M., Parker, G., Orange, D., Locat, J., Hutton, E. and Imran, J. (2002) Distinguishing sediment waves from slope failure deposits: field examples, including the 'Humboldt slide', and modeling results. Mar. Geol., 192, 79-104.

Li, L. and Gong, C. (2018) Gradual Transition From Net Erosional to Net Depositional Cyclic Steps Along the Submarine Distributary Channel Thalweg in the Rio Muni Basin: A Joint 3-D Seismic and Numerical Approach Journal of Geophysical Research: Earth Surface, 123, 2087-2106.

Li, M.Z. and King, E.L. (2007) Multibeam bathymetric investigations of the morphology of sand ridges and associated bedforms and their relation to storm processes, Sable Island Bank, Scotian Shelf. Mar. Geol., 243, 200-228.

Massari, F. (2017) Supercritical-flow structures (backset-bedded sets and sediment waves) on high-gradient clinoform systems influenced by shallow-marine hydrodynamics. Sediment. Geol., 360, 73-95

Massari, F. and Parea, G.C. (1990) Wavedominated Gilbert-type gravel deltas in the hinterland of the Gulf of Taranto (Pleistocene, southern Italy). In : Coarse-grained deltas (Eds A. Colella and D.B. Prior), IAS Spec. Pub., pp. 311-331, Blackwell Scientific Publication, Oxford.

Mastbergen, D.R. and Van Den Berg, J.H. (2003) Breaching in fine sands and the generation of sustained turbidity currents in 
submarine canyons. Sedimentology, 50, 625637.

McKee, E.D. (1965) Experiments on ripple lamination. In: Primary sedimentary structures and their hydrodynamic interpretation (Ed. G.W. Middelton). Soc. Econ. Paleont. and Mineral., Spec. Pub. n 12, 66-83.

Migeon, S., Savoye, B., Zanella, E., Mulder, T., Faugères, J.C. and Weber, O. (2001) Detailed seismic-reflection and sedimentary study of turbidite sediment waves on the Var Sedimentary Ridge (SE France): significance for sediment transport and deposition and for the mechanism $\mathrm{s}$ of sediment-wave construction. Mar. Petr. Geol., 18, 179-208.

Migeon, S., Mulder, T., Savoye, B. and Sage, F. (2012) Hydrodynamic processes, velocity structure and stratification in natural turbidity currents: Results inferred from field data in the Var Turbidite System. Sediment. Geol., 245-246, 48-62.

Mulder, T., Syvitski, J.P.M., Migeon, S., Faugères, J.-C. and Savoye, B. (2003) Marine hyperpycnal flows: initiation, behavior and related deposits. A review. Mar. Petrol. Geo., 20, 861-882.

Normandeau, A., Lajeunesse, P., St-Onge, G., Bourgault, D., Drouin, S.S.O., Senneville, S. and Bélanger, S. (2014) Morphodynamics in sediment-starved inner-shelf submarine canyons (Lower St. Lawrence Estuary, Eastern Canada). Mar. Geol., 357, 243-255.

Normandeau, A., Lajeunesse, P., Poiré, A.G. and Francus, P. (2016) Morphological expression of bedforms formed by supercritical sediment density flows on four fjord-lake deltas of the south-eastern Canadian Shield (Eastern Canada). Sedimentology, 63, 2106-2129.

Normandeau, A., Dietrich, P., Lajeunesse, P., St-Onge, G., Ghienne, J.-F., Duchesne, M.J. and Francus, P. (2017) Timing and controls on the delivery of coarse sediment to deltas and submarine fans on a formerly glaciated coast and shelf. Geol. Soc. Am. Bull., 129, 1424-1441.

Normandeau, A. et al. (2018) CCGS Hudson Expedition 2018042: Marine geohazards and natural seeps off southeastern Baffin Island. Geological Survey of Canada Open File 8488, $91 \mathrm{p}$.

Normandeau, A., Dietrich, P., Hughe Clarke, J.H., Van Wychen, W., Lajeunesse, P., Burgess, D. and Ghienne, J.-F. (2019). Retreat pattern of glaciers controls the occurrence of turbidity currents on highlatitude fjord deltas (eastern Baffin Island). $J$. Geophys. Res. Earth Surface, 124, 1559-1571.

Normandeau, A., Bourgault, D., Neumeier, U., Lajeunesse, P., St-Onge, G., Gostiaux, L. and Chavanne, C. (2020). Storm-induced turbidity currents on a sediment-starved shelf: insight from direct monitoring and repeat seabed mapping of upslope migrating bedforms. Sedimentology, 67, 1045-1068.

Normark, W.R., Piper, D.J.W., Posamentier, H., Pirmez, C. and Migeon, S. (2002) Variability in form and growth of sediment waves on turbidite channel levees. Mar. Geol., 192, $23-58$.

Nutz, A., Ghienne, J.-F., Schuster, M., Roquin, C., Bouchette, F. and Cousineau, P.A. (2015) Forced regressive deposits within a deglaciation sequence: example of the Late Quaternary succession in the Lake Saint-Jean basin (Québec, Canada). Sedimentology, 62, 1573-1610.

Occhietti, S., Parent, M., Lajeunesse, P., Robert, F. and Govare, É. (2011) Late Pleistocene-Early Holocene Decay of the Laurentide Ice Sheet in Québec-Labrador. In: Quaternary Glaciations - Extent and Chronology (Eds J. Ehlers, P.L. Gibbard, P.D. Hughes), Vol. 15, pp. 601-630. Elsevier, Amsterdam, the Netherlands.

Ono, K. and Plink-Björklund, P. (2018) Froude supercritical flow bedforms in deepwater slope channels? Field examples in conglomerates, sandstones and fine-grained deposits. Sedimentology, 65, 639-669.

Ono, K., Plink-Björklund, P., Eggenhuisen, J. and Cartigny, M.J.B. (in press) Froude supercritical flow processes and sedimentary structures: new insights from experiments with a wide range of grain sizes. Sedimentology.

Parker, G. (1996) Some Speculations on the Relation Between Channel Morphology and Channel-scale Flow Structures. Proceedings, Coherent flow structures in open channels, 423, 424-458.

Parker, G., Fukushima, Y. and Pantin, M. (1986) Self-accelerating turbidity currents. J. Fluid Mech., 171, 145-181.

Paull, C.K., Talling, P.J., Maier, K.L. et al. (2018) Powerful turbidity currents driven by dense basal layers. Nat. Comm., 9, 4114. DOI: 10.1038/s41467-018-06254-6 [online]

Paull, C.K., Ussler Iii, W., Caress, D.W., Lundsten, E., Covault, J.A., Maier, K.L., Xu, J. and Augenstein, S. (2010) Origins of large crescent-shaped bedforms within the axial channel of Monterey Canyon, offshore California. Geosphere, 6, 755-774.

Pohl, F., Eggenhuisen, J.T., Tilston, M. and Cartigny, M.J.B. (2019) New flow relaxation mechanism explains scour fields at the end of submarine channels. Nat. Com., 10, 4425. DOI: 10.1038/s41467-019-12389-x [online] 
Postma, G., Nemec, W. and Kleinspehn, K.L. (1988) Large floating casts in turbidites: a mechanism for their emplacement. Sediment. Geol., 58, 47-61.

Postma, G., Cartigny, M. and Kleverlaan, K. (2009) Structureless, coarse-tail graded Bouma Ta formed by internal hydraulic jump of the turbidity current? Sediment Geol., 219, 1-6.

Postma, G. and Cartigny, M.J.B. (2014) Supercritical and subcritical turbidity currents and their deposits-A synthesis. Geology, 42, 987-990.

Postma, G., Kleverlaan, K. and Cartigny, M.J.B. (2014) Recognition of cyclic steps in sandy and gravelly turbidite sequences, and consequences for the Bouma facies model. Sedimentology, 61, 2268-2290.

Praeg, D., d'Anglejan, B. and Syvitski, J.P.M. (1992) Seismostratigraphy of the Middle St. Lawrence Estuary: A Late Quaternary Glacial Marine to Estuarine Depositional/Erosional Record. Géogr. phys. Quatern., 46, 133-150.

Sequeiros, O.E., Spinewine, B., Garcia, M.H., Beaubouef, R.T., Sun, T. and Parker, G. (2009) Experiments on Wedge-Shaped Deep Sea Sedimentary Deposits in Minibasins and/or on Channel Levees Emplaced by Turbidity Currents. Part I. Documentation of the Flow. J. Sediment. Res., 79, 593-607.

Slootman, A. and Cartigny, M.J.B. (2020) Cyclic steps: Review and aggradation-based classification. Earth-Sci. Rev., 201 (in press)

Slootman, A., De Boer, P.L., Cartigny, M.J.B., Samankassou, E. and Moscariello, A. (2019) Evolution of a carbonate delta generated by gateway-funneling of episodic currents. Sedimentology, 66, 1032-1340.

Smith, D.P., Ruiz, G., Kvitek, R. and Iampietro P.J. (2005) Semiannual patterns of erosion and deposition in upper Monterey Canyon from serial multibeam bathymetry. Geol. Soc. Am. Bull., 117, 1123-1133.

Spinewine, B., Sequeiros, O.E., Garcia, M.H., Beaubouef, R.T., Sun, T., Savoye, B. and Parker, G. (2009) Experiments on WedgeShaped Deep Sea Sedimentary Deposits in Minibasins and/or on Channel Levees Emplaced by Turbidity Currents. Part II. Morphodynamic Evolution of the Wedge and of the Associated Bedforms. J. Sediment. Res., 79, 608-628.

Swift, D.J.P., Parsons, B.S., Foyle, A. and Oertel, G.F. (2003) Between beds and sequences: stratigraphic organization at intermediate scales in the Quaternary of the Virginia coast, USA. Sedimentology, 50, 81111.
Symons, W.O., Sumner, E.J., Talling, P., Cartigny, M.J.B and Clare, M.A. (2016) Large-scale sediment waves and scours on the modern seafloor and their implications for the prevalence of supercritical flows. Mar. Geol., 371, 130-148.

Syvitski, J.P.M. (1989) On the deposition of sediment within glacier-influenced fjords: Oceanographic controls. Mar. Geol., 85, 301329.

Syvitski, J.P.M. and Praeg, D. (1989) Quaternary Sedimentation in the St. Lawrence Estuary and Adjoining Areas, Eastern Canada: An Overview Based on High-Resolution Seismo-Stratigraphy. Géogr. phys. Quatern., 43, 291-310.

Talling, P.J., Masson, D.G., Sumner, E.J. and Malgesini, G. (2012) Subaqueous sediment density flows: Depositional processes and deposit types. Sedimentology, 59, 1937-2003.

Talling, P., Allin, J., Armitage D.A. et al. (2015) Key future directions for research on turbidity currents and their deposits. J. Sediment. Res., 85, 153-169.

Tarasov, L., Dyke, A.S., Neal, R.M. and Peltier, W.R. (2012) A data-calibrated distribution of deglacial chronologies for the North American ice complex from glaciological modeling. Earth. Planet. Sci. Let., 315-316, 30-40.

Trottier, A.-P., Lajeunesse, P., Gagnon-Poiré, A. and Francus, P. (2020) Morphological signatures of deglaciation and postglacial sedimentary processes in a deep fjord-lake (Grand Lake, Labrador). Earth Surf. Process. Landforms, 45, 928-947.

Tubau, X., Paull, C.K., Lastras, G., Caress, D.W., Canals, M., Lundsten, E., Anderson. K., Gwiazda, R. and Amblas, D. (2015) Submarine canyons of Santa Monica Bay, Southern California: Variability in morphology and sedimentary processes. Mar. Geol., 365, 61-79.

Turmel, D., Locat, J. and Parker, G. (2015) Morphological evolution of a well-constrained, subaerial-subaqueous source to sink system: Wabush Lake. Sedimentology, 62, 1636-1664.

Vellinga, A.J., Cartigny, M.J.B., Eggenhuisen, J.T. and Hansen, E.W.M. (2018) Morphodynamics and depositional signature of low-aggradation cyclic steps: New insights from a depth-resolved numerical model. Sedimentology, 65, 540-560.

Vendettuoli, D., Clare, M.A., Hughes Clarke, J.E. et al. (2019) Daily bathymetric surveys document how stratigraphy is built and its extreme incompleteness in submarine channels. Earth Planet. Sci. Letters, 515, 231247. 
Ventra, D., Cartigny, M.J.B., Bijkerk, J. and Acikalin, S. (2015) Supercritical-flow structures on Late Carboniferous delta front: Sedimentologic and paleoclimatic significance. Geology, 43, 731-734

Yokokawa, M., Okuno, K., Nakamura, A., Muto, T., Miyata, Y., Naruse, H. and Parker, G. (2009) Aggradational cyclic steps: sedimentary structures found in flume experiments. In : International Association for Hydro-Environment Engineering and Research, 33rd Congress, Proceedings. pp. 5547-5554.

Yokokawa, M., Takahashi, Y., Yamamura, H., Kishima, Y., Parker, G. and Izumi, N. (2011) Phase diagram for antidunes and cyclic steps based on suspension index, non-dimensional Chezy resistance coefficient and Froude number. In : International Association for Hydro-Environment Engineering and Research, 7th Symposium on River, Coastal and Estuarine Morphodynamics, Beijing, China (RCEM 2011), Proceedings. pp. 17891794.

West, L.M., Perillo, M.M., Olariu, C. and Steel, R.J. (2019) Multi-event organization of deepwater sediments into bedforms: Longlived, large-scale antidotes preserved in deepwater slopes. Geology, 47, 391-394.

Zhong, G., Cartigny, M.J.B., Kuang, Z. and Wang, L. (2015) Cyclic steps along the South Taiwan Shoal and West Penghu submarine canyons on the northeastern continental slope of the South China Sea. Geol. Soc. Am. Bull., 127, 804-824. 